\title{
Bargaining at Retail Stores: Evidence from Vienna*
}

\author{
Sandro Shelegia ${ }^{\dagger} \quad$ Joshua Sherman ${ }^{\ddagger}$
}

January 14, 2018

\begin{abstract}
The optimality of trading mechanisms has long been a subject of interest in economics, yet there exists little empirical evidence regarding which mechanisms of trade are deployed in practice. Our audit study of retail stores in Vienna documents previously unknown and important facts. Stores agree to a discount off of the posted price approximately $40 \%$ of the time. Discounts are more likely to be granted by small-scale firms, for higher-priced products, and for non-sale items. Our findings are consistent with the predictions of a principle-agent model in which a firm decides whether to augment posted prices with bargaining concessions.
\end{abstract}

JEL Classification: L81; D12; C78; C93.

Keywords: Bargaining; Posted Price; Trading Mechanism; Audit Study.

\footnotetext{
*Substantial work on this paper was performed while the authors were at the University of Vienna. We owe many thanks to 24 auditors and research assistants who worked in various capacities on this project. We would like to thank Larbi Alaoui, Ayala Arad, Daniel Garcia, Maarten Janssen, Wieland Mueller, Karl Schlag, Philipp Schmidt-Dengler, Adriaan Soetevent, James Tremewan, and Jean-Robert Tyran for helpful suggestions. We also thank workshop participants at Israel IO Day at Tel Aviv University and the Search Cost Workshop at the University of Groningen, as well as seminar participants at the University of Innsbruck, the Illinois Institute of Technology, the University of Bologna, the U.S. Department of Justice, Bar-Ilan University, Ben Gurion University, IDC Herzliya, Tel Aviv University, and the University of Haifa. Assistance provided by Sylvie Hansbauer and Andrea Neidhart was very much appreciated. We gratefully acknowledge financial support from the economics department at the University of Vienna. Shelegia acknowledges financial support from the Spanish Ministry of Science and Innovation grant MINECO ECO2014-59225-P. Shelegia acknowledges financial support from the Spanish Ministry of Economy and Competitiveness, through the Severo Ochoa Programme for Centres of Excellence in RD (SEV-2015-0563).

${ }^{\dagger}$ Department of Economics, Pompeu Fabra University and Barcelona Graduate School of Economics. Email: sandro.shelegia@upf.edu

${ }^{\ddagger}$ Compass Lexecon and Department of Economics, Northwestern University. Email: joshua.sherman@kellogg.northwestern.edu
} 


\section{Introduction}

Given the prevalence of posted prices in the Western world, it is easy to forget that they are a relatively recent phenomenon in the history of commerce. The first documented instance in the world occurred in Tokyo in 1673 and the first documented instance in the West occurred in New York in 1823 (Mahoney and Sloane (1966)). Since then, posted prices have become the norm for retail goods sold in developed countries.

Naturally, economists have been interested in understanding trading mechanisms in general, and in particular, explaining why and how posted prices have emerged as the dominant mechanism. Riley and Zeckhauser (1983) showed that a firm that sells a single unit to a sequence of buyers prefers committing to a take-it-or-leave-it posted price for all buyers to any alternative selling mechanism, including bargaining. ${ }^{1}$ Several studies have examined the more specific question of whether firms prefer bargaining with alternating offers to a posted price and have found that a posted price may emerge in equilibrium, even if bargaining is also possible. ${ }^{2}$

In a world in which posted prices are prevalent, however, the firm's choice of trading mechanism is not necessarily a question of either/or. Even though posted prices are the norm in retail, there is recent evidence that some retailers grant requests to consumers who ask for discounts below the posted price, at least for some products. ${ }^{3}$ Until now, no formal study has looked at the prevalence of non-posted prices in the West, nor has any study related such practices to firm and product characteristics in order to find patterns consistent with existing theories, such as those noted above. ${ }^{4}$

This paper fills this gap with a novel hand-collected data set that documents the outcomes of interactions between trained auditors and retail store employees throughout Vienna, Austria. In order to set the stage, it is useful to first report the results of a separate, auxiliary survey of consumers that we conducted upon their exit from the same stores that were visited during the audit study. We found that $6 \%$ of consumers said that they had just asked for a discount below the product's posted price (Table 1). This finding alone suggests that in most consumer markets (outside of, for example, automobile markets, where bargaining is the norm), the relevant theoretical and empirical question is the following: Under which circumstances does a firm choose to bargain with some consumers in addition to posting a unit price for all others? While a small collection of recent theoretical papers has begun to address this question, very little on the subject is known empirically. In particular, we would like to understand which

\footnotetext{
${ }^{1}$ In related settings, similar results were obtained by Myerson (1981), Sobel and Takahashi (1983), and Perry (1986).

${ }^{2}$ For example, Bester (1993) considers a market for an experience good and shows that the posted price mechanism increases the probability of trade but reduces sellers' incentives to provide high quality relative to bargaining. Other studies that compare posted prices with bargaining include Wang (1995) and Arnold and Lippman (1998), who both study a monopoly seller which sells one unit of an indivisible good to many potential buyers. Other related studies include Camera and Delacroix (2004) and Raskovich (2007).

${ }^{3}$ The New York Times (December 15, 2013), The Independent (March 29, 2015) and other news outlets have recently addressed the phenomenon of haggling at retail stores in a casual, anecdotal manner and found that retail stores such as Best Buy, Home Depot, Nordstrom, and Bloomingdales were willing to give a discount when asked.

${ }^{4}$ See Footnote 11 for a summary of the related theoretical literature.
} 
price and firm characteristics induce firms to augment their posted prices with personalized discounts upon a consumer's request.

Table 1: Consumer survey results

Respondent
Buyer
Non-buyer
Total

Respondent
Buyer
Non-buyer
Total

Asked for a discount

All respondents

Asked for
13
4
17

Asked for a discount

22
Firm type: Domestic

\begin{tabular}{ccc}
\multicolumn{2}{c}{ Firm type: Multinational } & \\
Asked for a discount & Consumers surveyed & Percentage \\
4 & 59 & $6.8 \%$ \\
1 & 79 & $1.3 \%$ \\
5 & 138 & $3.6 \%$
\end{tabular}

Percentage

$12.5 \%$

$2.9 \%$

$7.0 \%$

Consumers surveyed 380

Percentage $5.8 \%$

Note: Buyers are those who reported purchasing from the store on that visit. Information regarding the way in which firms were classified as domestic or multinational is provided later in the study in footnote 27 .

This brings us to a summary of our findings from our audit study in which trained auditors posed as customers and asked for discounts off of the posted price at a wide variety of retail establishments in Vienna. In this regard we are able to document a few very surprising findings. In particular, a discount was offered approximately $40 \%$ of the time overall (303 of 751 products). ${ }^{5}$ Including instances in which no discount was granted, the average discount was approximately 10 EUR and the average discount percentage was approximately $4.8 \%$ (goods collectively priced at approximately 159,516 EUR were offered to be discounted by approximately 7,715 EUR). Conditional on a discount being offered, the average discount size was approximately $25 \mathrm{EUR}$, and the simple average positive discount percentage (and median positive discount percentage) was approximately $10 \%{ }^{6}$

While the frequency and size of discounting that we found was interesting in and of itself, we also seek to understand the firm-side factors that drive this behavior using data on various store characteristics (e.g., store size) as well as price characteristics (some of the items surveyed were advertised as sale items). Given our interest in the determinants of bargaining propensity from the firm's perspective in posted-price settings, it is therefore advantageous that in practice a non-trivial fraction of consumers ask for a discount (so that stores must formulate a policy with regards to such consumers) yet this fraction is not so high as to affect store and price

\footnotetext{
${ }^{5}$ In order to get a sense for the types of products for which a discount was granted, here we provide a list of 10 products taken from 303 such instances: a backpack, a blanket, a cordless screwdriver, a kite, a manicure set, a bottle of perfume, a scarf, a stuffed animal, a surveillance camera for babies, and a sweater. A complete list of every product observed is available from the authors upon request.

${ }^{6}$ Given an average unconditional discount of 10 EUR and an average conditional discount of 25 EUR, it is interesting to note that Jindal and Newberry (2017) estimate that the average consumer bargaining cost for refrigerators amounts to $\$ 28$.
} 
characteristics in a meaningful way. This simplifies the task of isolating factors that influence a firm's propensity to bargain from the firm's pricing and organizational decisions. ${ }^{7}$

Turning to our main empirical findings, we estimate that the probability of a discount increases with the price of the good, is lower for sale items, and is lower at large-scale firms (firms with many branches or firms with multinational reach). The first finding is consistent with the notion that a higher price is associated with a higher (absolute) margin, something that we would expect given a large cross-section of diverse products sold at retail stores. ${ }^{8}$ The second finding suggests that products on sale have lower margins than identically priced goods that are not on sale. ${ }^{9}$ Such an inference would be consistent with several possible interpretations of sales, including the possibility that sales reflect discrepancies in demand rather than costs. The third finding is consistent with the notion that per-employee monitoring costs are higher at large-scale firms, a view that is well-supported across the literature dealing with firm size and control-loss. Later, we claim that higher per-employee monitoring costs will imply that employees at large-scale firms, if given discretion to grant discounts, will not apportion them optimally (from the firm's perspective). Along these lines, we also find that a discount is more likely to be granted at a firm with few visible employees. In addition, we find that the difference in probability of earning a discount at a small-scale firm vs. a large-scale firm tends to be larger at higher price levels, in line with our theory.

We also find that when a discount is granted, the amount of a discount increases with the price of the good; we estimate that the elasticity of discount size with respect to price is approximately unitary. Interestingly, stores which were observed with no customers for a three minute period prior to the data collection stage give substantially larger discounts. Generally speaking, firms did not decide to grant a discount on the basis of auditor identity or auditor gender.

To help contextualize our empirical study, we write down a simple theoretical model in which we interpret bargaining as a tool used by a firm owner in conjunction with a posted price in order to discriminate between consumers with different valuations for a product. ${ }^{10}$ In particular, we consider a firm selling many units of a particular good that chooses a posted price. The owner of the firm decides whether or not to allow a salesperson to give discounts to consumers who ask for it (to whom we will refer as hagglers). In this simple environment, the owner's decision to allow bargaining for a particular product will depend on a number of

\footnotetext{
${ }^{7}$ For example, it is conceivable that a firm that intends to bargain on prices with a large fraction of consumers would set a deliberately high posted price (as the starting point of any such negotiation). However, in our setting the fraction of consumers who ask for discounts is low enough so that posted prices are chosen predominantly for consumers who do not ask for discounts, and therefore purposeful distortion of prices upwards would not be a sensible strategy in our empirical setting. We revisit this theoretical issue in footnote 18.

${ }^{8}$ In a different context, evidence of the relationship between prices and margins for cars in Berry et al. (1995) is also informative. We shall address this relationship in further detail later in the study.

${ }^{9}$ Note that this statement does not concern a comparison of margins on the same product before and after a sale, but rather two products currently priced at the same level, one on sale from a previously higher price and one not on sale.

${ }^{10}$ Even though we employ the term bargaining to describe interactions in our theoretical model as well as in our empirical study, one may also contextualize such interactions as a form of price discrimination upon a consumer's request.
} 
factors, including the price of the good, the degree to which the salesperson's response to a haggler is optimal (from the owner's perspective), and the firm's (direct) cost of bargaining. ${ }^{11}$

In order to analyze the drivers of a firm's propensity to bargain, we hired 12 auditors to visit nearly 300 diverse retail stores in four different commercial areas of Vienna and ask for discounts off of posted prices. The auditors were assigned specific stores to visit, find a product in a pre-specified price range, feign credible interest in that product and then ask for a discount. Products surveyed ranged from a posted price of 30 EUR to 999.99 EUR, with a median posted price in the data of 135 EUR. As a result, we were able to collect observations that pertain to a diverse pool of price and firm characteristics and use this information in order to analyze the determinants of a firm's propensity to bargain.

\section{Literature review}

It is useful to place our work in the context of a wider empirical literature. Outside of studies of trade via the internet, we are unaware of any existing empirical work examining the firmside factors that influence the trading mechanism decision in a retail setting. ${ }^{12}$ Our paper is closest to a growing literature on bargaining in product markets, however, there are important differences. ${ }^{13}$ The early focus of this literature is on the automobile market, where bargaining is widespread. In their pioneering work, Ayres (1991) and Ayres and Siegelman (1995) conducted a series of studies by sending hypothetical consumers to car dealerships in Chicago. They found that blacks and females received significantly worse price quotes than white males, whereas in an empirical analysis of automobile purchase data Goldberg (1996) did not find clear evidence of discrimination. ${ }^{14}$ List (2004) examined bargaining in a sportscard market and found that minorities receive considerably worse offers but that discrimination is statistical in nature. Backus et al. (2016) find that the seller's round price signals its willingness to cut price on eBay, where many transactions are made via bargaining. Other studies that have focused

\footnotetext{
${ }^{11}$ Perhaps the closest theoretical papers are Desai and Purohit (2004), Gill and Thanassoulis (2009) and Gill and Thanassoulis (2016), who consider an oligopoly with two types of consumers, hagglers and non-hagglers. In Desai and Purohit (2004), two firms can choose to bargain with hagglers while they charge a (higher) posted price to non-hagglers. Our monopoly model is similar with the crucial difference that if no agreement is reached with a haggler, the haggler may still purchase at the posted price. Gill and Thanassoulis (2009) study an oligopoly where the price for non-hagglers is determined via Cournot competition. Hagglers may request discounts from multiple firms simultaneously while taking the best offer, and as a result discounts are randomized in equilibrium. In Gill and Thanassoulis (2016) firms post prices to non-hagglers and give random discounts to hagglers. They show that the presence of hagglers raises all prices and facilitates collusion. Finally, Raskovich (2007) studies a related model where firms with homogeneous goods post price and negotiate with hagglers.

${ }^{12}$ We should note that the choice of auction formats by sellers has been studied in timber markets (Athey et al. (2011)), on eBay (Wang et al. (2008), Hammond (2010), Einav et al. (2013) and Bauner (2015)) and for online advertisements (Ostrovsky and Schwarz (2011)).

${ }^{13}$ There is a large body of work that focuses on discrimination in labor and real estate markets. See Riach and Rich (2002) for a comprehensive survey.

${ }^{14}$ Several other authors have studied car negotiation outcomes. Scott Morton et al. (2011) find that buyer search cost and bargaining disutility have significant effects on the purchasing price. In particular, they find that consumers with a low bargaining disutility pay $\$ 261$ less on average than consumers with a high bargaining disuitility. Huang (2010) estimates the profitability of no-haggle prices vs haggling for car dealerships. Huang (2010) does not observe transaction prices for haggling dealers and does not model bargaining explicitly.
} 
on bargaining include Keniston (2011) (autorickshaw rides in Jaipur, India), Zussman (2013) (cars), Castillo et al. (2013) (taxi rides in Lima, Peru), Bengtsson (2015) (taxi rides in Cape Town, South Africa), and Iyer et al. (2016) (tailoring stores in Chennai, India). ${ }^{15}$ Finally, Jindal and Newberry (2017) study bargaining outcomes for refrigerators at an appliance retailer. In their sample, $92 \%$ of consumers bargain the posted price down, whereas the remaining consumers pay the posted price. Jindal and Newberry (2017) use this variation to estimate consumers' bargaining costs and bargaining power. ${ }^{16}$ Therefore, while previous studies have analyzed firm bargaining behavior in individual markets where bargaining is the norm and most have focused on consumer variation, we study a large collection of diverse firms in markets where a majority of transactions take place at the posted price, focusing on how price and firm variation influences the likelihood of a discount being granted.

The paper is structured as follows. Section 2 offers a theoretical framework for purposes of understanding the incentives of a firm to agree to grant a discount. Section 3 introduces the study design and Section 4 discusses the empirical analysis and results. Section 5 concludes.

\section{Theoretical Framework}

Given that nearly all existing theoretical literature on the firm's choice between a posted price and bargaining examines the question as an either/or decision, and given that the small set of literature that allows for both implicitly or explicitly focuses on how the proportion of hagglers (which in our setting is small and fixed) influences the firm's bargaining strategy, we feel that it is informative to contextualize our empirical analysis with the aid of a simple theoretical framework. Along these lines, it is important to note that it is not our objective to offer an all-encompassing theory of bargaining at retail stores. Indeed, there likely exist several conceivable ways in which one might consider modelling a retail firm's decision regarding whether to augment a posted price with a discount. Nevertheless, we believe that the following framework captures several important determinants of a firm's willingness to grant a discount.

In what follows, we shall present the outline of our model as well as its primary predictions and allocate the majority of the analysis to Appendix A for interested readers. But first, we introduce particular details of our empirical environment in order to provide motivation for the model.

\subsection{Background}

An auditor enters an assigned retail store and poses as a consumer with an interest to purchase a product. Upon noting the posted price of the product, the auditor approaches the nearest salesperson and engages in a brief interaction in order to request a discount off of the posted price. The salesperson then either denies the request or approves it with a lower price offer.

\footnotetext{
${ }^{15}$ The latter is different from the literature in that rather than focusing on discrimination, the authors examine how regulation affects bargaining outcomes and consider welfare properties of bargaining.

${ }^{16}$ In a related study Zhang et al. (2017) estimate a structural model of bargaining and posted prices using data from Taobao to find that sellers would be better off if bargaining was disallowed.
} 
We discuss these interactions as well as the design of our audit study in more detail in Section 3 .

Empirically, we observe a wide variety of retail stores selling a diverse range of products at various price levels. Therefore, we will need to formulate a theoretical model in which a firm determines how its salespeople should respond to discount requests. In particular, a given firm may prefer to bargain for certain products but not for others.

\section{Employee monitoring costs}

Given that we are particularly interested in the effect of the firm's characteristics on its willingness to bargain, it is important to consider previous findings regarding the relationship between firm scale and employee monitoring costs. In a seminal study, Williamson (1967) shows that communication difficulties across successive hierarchical levels are a prime contributor to diminishing returns to scale. Subsequently, Calvo and Wellisz (1978) show that the hierarchical loss of control discussed by Williamson (1967) rests on the assumption that employees are generally aware of when they are being monitored. In particular, as the scale of the firm increases, additional hierarchies must be introduced. These additional hierarchies imply that monitoring costs increase at an increasing rate. Radner and Van Zandt (1995) summarize the literature in this area by stating that the need for employee monitoring leads to decreasing returns to scale because the addition of new employees at the base of a hierarchy either ultimately increases the number of hierarchical levels or increases the number of employees who are under supervision of a given monitor. Either way, an increase in firm scale ultimately leads to a loss of control over the firm's employees.

The theoretical literature on the topic is supported by a recent survey by Ortega (2009) of several thousand employees at firms throughout Western Europe, which finds that employees at small establishments are given significantly more discretion than employees at large establishments. An earlier study by Schmidt and Zimmerman (1991) based on a survey of 891 employed individuals in West Germany also argues that monitoring costs are likely higher at medium/large-scale firms. We conclude from the preponderance of evidence on the topic that monitoring is more costly on a per-employee basis at large-scale firms.

There exist several ways in which a large-scale firm may address this difficulty. One option is for large-scale firms to tolerate the ramifications of relatively unmonitored employees (due to the high costs of monitoring), which implies that some employees will engage in actions which are not optimal for the firm. In our context, this would imply that employees may sometimes grant discounts to customers who do not actually require discounts in order to purchase and in other cases refuse discounts to consumers who will not purchase at the posted price. In either case, these actions may occur due to an employee's error in judgment or due to misaligned incentives between the firm's owner and the employee. Another option is to tolerate unmonitored employees but to completely forbid bargaining in expectation that unmonitored employees will not always act in the best interests (knowingly or unknowingly) of the firm. While a blanket prohibition on bargaining may not be easy to monitor in and of 
itself, it is certainly easier to ensure that such a policy is carried out than monitoring whether each individual request for a discount is responded to optimally. A third possibility is to set strict guidelines for granting a discount that may be more easily monitored, such as restricting employees to granting a fixed percentage discount when the customer convinces them that they will not pay the posted price. Indeed, we will present empirical evidence of such a phenomenon at large-scale firms later in the study. Finally, given that the literature suggests that monitoring costs increase on a per-employee basis as firm size increases, the firm could choose to incur these costs as it grows in order to allow each employee at a large-scale firm the same discretion given to an employee at a small single-location store. However, even if this type of micromanagement were feasible or credibly supported by anecdotal evidence, it seems unlikely that this would be an optimal approach for the firm.

Regardless of which of these first three proposed approaches is adopted by the firm, the preceding discussion implies that if permitted to grant discounts at their discretion, employees at large-scale firms will not grant them optimally (from the firm's perspective) due to the costs associated with monitoring employees at large-scale firms.

\section{Competition}

While retailers in our sample face varying degrees of competition, for simplicity we shall only consider a monopolist in the context of our theory. In reality, firms face varying degrees of competition. It is therefore reasonable to ask whether we should consider an oligopolistic framework instead. The answer to this question depends on whether one believes that an increase in competition reduces the posted price. If competition pushes the posted price downward, then a consumer's threat of not purchasing at the posted price due to an outside option would be addressed via a posted price reduction. On the other hand, if competition did not influence the posted price, then a firm should be more willing to grant a discount to a consumer when the consumer could (credibly) threaten to purchase from a competitor instead.

Given that hagglers comprise a small proportion of the population of consumers in the type of environment which we have in mind, it is not unreasonable to assume that competition influences the posted price of the retail firms we examine, which would in turn depress the willingness of such firms to grant discounts. Therefore, to the extent that competition influences a firm's willingness to bargain, for our purposes we view any such effects to be transmitted via the posted price, which would consequently decrease the firm's willingness to grant a discount. Thus, given our empirical setting of interest, theoretically analyzing the firm's decision outside of a monopoly framework would add considerable complexity with little benefit in this context. Furthermore, for simplicity we shall study a monopolist that sells a single good rather than multiple goods.

\section{Delays}

It is important to note outright that in our setting, we consider bargaining as a firm's attempt to price discriminate among heterogeneous consumers. This view is shared in the theoretical 
literature on endogenous choice of pricing mechanisms, where bargaining is studied as a costly discrimination tool because it allows a firm to obtain additional information (via interaction with the consumer) about the consumer's willingness to pay. ${ }^{17}$ Based on this tradition, and given that it closely corresponds to our empirical setting, we will assume away any issues related to delays and the consumer's discount factor.

\subsection{Simple model}

We now introduce a simple theoretical model that will allow us to contextualize our empirical analysis.

We envision a firm that sells a good to many consumers. Most consumers do not haggle and take the posted price of the good, $p$, as given. In this study we model $p$ as exogenous to the firm's bargaining decision because consumers who bargain constitute a small fraction of the population in our empirical environment. ${ }^{18}$ In our model we will normalize the firm's marginal cost of production to zero, and therefore $p$ is also the firm's margin.

Even though hagglers are a small proportion of the population, they are numerous enough such that the firm's owner must determine how to respond to their requests for a discount. We assume that hagglers always attempt to bargain, regardless of their willingness to pay the posted price and regardless of the firm's policy regarding haggling. Hagglers' valuations, denoted by $v$, are distributed in the following way. With probability $0<\mu<1$ a haggler's valuation exceeds $p$. With probability $1-\mu$ a haggler's valuation is distributed uniformly on the interval $[0, p]{ }^{19}$ Therefore, $\mu$ is the probability that the posted price $p$ would be acceptable to a haggler. ${ }^{20}$

The owner employs a clerk. When a haggler with a valuation $v$ approaches the clerk, we assume that the clerk receives a noisy signal $s$ that is related to the true $v$ in the following way. With probability $\lambda$, it is equal to $v$. With probability $1-\lambda, s$ is completely unrelated to $v$ and is randomly drawn from the same distribution as $v \cdot{ }^{21}$ Given this structure, the distribution of $s$ is identical to the distribution of $v$ for any level of $\lambda$. Thus, while clerks with different levels of $\lambda$ differ in how effectively they judge $v$, on average their perception of consumers is correct. The parameter $\lambda$, therefore, measures how accurately the clerk is willing or able to estimate $v$, which in a more evolved model would depend on the owner's monitoring technology. ${ }^{22}$ We

\footnotetext{
${ }^{17}$ E.g. see Bester (1994), Wang (1995), and Arnold and Lippman (1998).

${ }^{18}$ In an earlier version of our paper we considered a model where $p$ was chosen endogenously according to the proportion of hagglers faced by the firm, and in such a model it is easy to show that the firm's pricing decision is made essentially without taking hagglers into consideration when the proportion of hagglers is low (e.g., when the proportion of hagglers is $6 \%$, as suggested by our consumer survey).

${ }^{19}$ The exact distribution of valuations above $p$ is inconsequential for the model. Alternatively, we could have assumed that valuations are uniformly distributed on the interval $\left[0, \frac{p}{(1-\mu)}\right]$. Our assumption of a uniform distribution for valuations below $p$ is made for simplicity and may be relaxed.

${ }^{20}$ Note that we implicitly assume that hagglers' valuations are never below the marginal cost (zero by assumption). This assumption may also be relaxed, but precluding this possibility simplifies our analysis.

${ }^{21}$ In the IO literature this signal technology is referred to as "truth or noise" (see, for example, Lewis and Sappington (1994) and Johnson and Myatt (2006)) and will prove to be very convenient for this model.

${ }^{22}$ Alternatively, one may interpret $\lambda$ as the probability that the clerk pays attention, in which case he infers $v$ perfectly, whereas he formulates a random estimate if he does not pay attention. One might also claim that
} 
also introduce another realistic lever that pushes against bargaining. In particular, we assume that the firm (i.e. the owner) suffers a cost $b$ every time a clerk agrees to grant a discount and a consumer purchases. For example, granting an individualized discount may be more time-consuming for the salesperson than selling a product at a posted price.

In order to introduce tension between the clerk and the owner, we shall assume that if the clerk is allowed to grant discounts, he bases his decision on $s$ as if it were a perfectly informative signal of $v$. This implies that the clerk does not use Bayesian updating. As a consequence, the clerk may grant a discount when it is not profitable for the firm, and a lower value of $\lambda$ will therefore imply a higher rate of mistakes. In addition, for simplicity we assume that the clerk does not take into account the cost $b$ when dealing with hagglers.

Given the clerk's behavior, the owner therefore has two choices: either allow the clerk to grant discounts in the way specified above, or to prohibit giving discounts altogether. In what follows, we present the primary predictions of the model, with analytical details provided in Appendix A.

\subsection{Predictions}

Price $(p)$ The owner is less likely to forbid bargaining for higher-priced (higher margin) items because the per-product profit for such items after bargaining will be more likely to exceed the fixed bargaining cost $b$. Put simply, the owner only wants to discriminate if potential gains are high enough.

The clerk's assessment of the customer $(\lambda)$ The owner is less likely to forbid bargaining when assured that the clerk will use his/her discretion to assess the customer in a manner that will be optimal for the firm. In particular, since we presume that owners of small-scale firms can monitor their employees at lower cost, clerks are more likely to respond to hagglers in a manner that is optimal from the firm's perspective (high $\lambda$ ) at small-scale firms.

The cost of bargaining (b) The higher the fixed cost of bargaining, the less likely it is that granting a discount will be profitable.

The probability that a haggler is willing to pay the posted price $(\mu)$ The more likely it is that the haggler will accept the posted price, the less attractive it is for the firm to allow its employees to grant discounts upon request.

Interaction between $p$ and $\lambda$ Intuitively, profits for higher-priced (higher margin) goods will be higher when a clerk responds to the consumer's request in a manner that is optimal for the firm (high $\lambda$ ).

The above predictions relate to a firm's bargaining policy. The comparative statics related to the likelihood of observing a discount granted (given that bargaining is not forbidden by the

the clerk's accuracy in assessing $v$ depends on the clerk's skills, his effort, the contract between the clerk and the owner, as well as other factors. Such potential extensions are beyond the scope of this study. 
firm) are similar and may also be found in Appendix A. Predictions related to discount size are also similar but subtle in certain cases, and are detailed in Appendix A as well.

\section{Study design}

First and foremost, Vienna served as a good location for purposes of conducting this study because it was the authors' place of residence prior to and during the data collection and because the authors are well-acquainted with the retail areas of the city. In addition, the retail shopping environment in Vienna is comparable to many large Western European and North American cities in that it consists of thousands of retail stores, from small independently owned stores to large multinational chains. The retail shopping culture in Vienna is also comparable to other Western cities in that most consumers in Vienna do not ask retailers for discounts. Therefore we considered Vienna to be an appropriate venue for purposes of studying how price and firm and characteristics influence a retailer's propensity to bargain.

The study design proceeded in several stages. First, we selected the geographic districts of Vienna to be studied. Vienna is comprised of 23 districts. We chose four distinct geographic areas that vary in average annual net income per person: the 1st district $(34,333 \mathrm{EUR}$, the wealthiest district), the 2nd (18,838 EUR, the 17th wealthiest district) and 20th $(17,334$ EUR, the 22nd wealthiest district) districts, the 18th (23,771 EUR, the 4th wealthiest district) and 19th $(25,372$ EUR, the 3rd wealthiest district) districts, and the 6th $(21,989$ EUR, the 12th wealthiest district) and 7th (22,659 EUR, the 8th wealthiest district) districts. ${ }^{23}$ The city's main shopping thoroughfare, Mariahilferstrasse, is located on the border between the 6th and 7th districts. Not only does the area around Mariahilferstrasse feature more stores than the other three areas, it is arguably the heart of commercial Vienna.

In order to construct a sample of stores to observe in each geographic area, research assistants (RAs) were instructed to record the name of every retail store on the main thoroughfares of these areas that met certain criteria. That is, stores that were service-focused (e.g. restaurants, salons, etc.), stores that primarily sell food or beverages, pharmacies, and highly specialized stores (e.g. hearing aids, orthopedic shoes) were not considered. Furthermore, the second highest price of a store was required to be at least $120 \mathrm{EUR}$; this would rule out stores such as "Tabak" shops, for example. Approximately 750 stores were recorded in total; approximately 300 stores were recorded in the 6 th and 7 th districts due to its commerical importance in Vienna, and approximately 150 stores were recorded in each of the remaining three areas. Those who were assigned to this task were not subsequently assigned to ask for discounts. Then, from each geographic area, a sample of $40 \%$ of the stores was selected at random for purposes of observation. Therefore the final sample consisted of 300 stores, although several stores needed to be discarded during the data collection phase for reasons to be noted later in the study.

Then, we searched for auditors who would be asked to seek discounts at stores by posting an advertisement in the building of the Faculty of Business, Economics, and Statistics at the

\footnotetext{
${ }^{23}$ Statistics obtained from Statistik Austria.
} 
University of Vienna and by sending an email with the same advertisement to the co-authors' former students. We hired the first six male and first six female German-fluent auditors for which we were able to schedule an interview. Several days before the beginning of the audit study, their first task was to visit approximately 20 stores each in order to record several pieces of information about each store; we refer to this as the "Information Gathering" stage.

The audit study was conducted starting in late 2013 and continued into the first week of 2014, and we split the study into two separate periods for two reasons. First, since the same stores were visited repeatedly, we wanted to allow for a break in between observations. The pre-Christmas and post-Christmas periods allowed for a natural pause in the data collection, and it also allowed us to the opportunity to examine whether a firm's bargaining behavior could provide an indication regarding the nature of post-Christmas sales. ${ }^{24}$

Three separate auditors were randomly assigned to each store in the sample using a stratified approach. More specifically, a random assignment was made with the following restrictions: each store was assigned a visit by at least one auditor of each gender, each store was assigned to be visited at least once both before and after Christmas, the observations of a given auditor were divided roughly evenly across the four geographic areas, and each auditor was assigned roughly the same number of observations before and after Christmas. Roughly half of the stores were assigned to be visited twice before Christmas and once following Christmas, and roughly half of the stores were assigned to be visited once before Christmas and twice following Christmas. In addition, a given auditor was not assigned to visit any stores previously visited during the information gathering stage.

If a store was assigned to be visited twice during the same shopping period, then arrangements were made in order to ensure that no store would be visited twice on the same day. The size of the price range observed, the number of stores visited, the number of visits per store, the areas of the city observed, and the number of auditors employed were dictated by budgetary constraints. Auditors were paid 12 EUR per hour. Along these lines, it is important to note that auditors were not incentivized monetarily according to the number of successful bargaining interactions as such an incentive would have created an incentive for auditors to fabricate their results. While incentivizing auditors based on successful bargaining interactions may have resulted in a higher number of discounts granted overall, the credibility of such data could be easily called into question.

Prior to the beginning of their work, each auditor was individually trained by one of the co-authors. The training entailed discussing the guidelines for their work, answering their questions, and bringing them to five stores that would not be observed during the study in order for them to practice requesting discounts. After each practice observation, the auditor discussed the interaction and any ambiguities surrounding the work was clarified. The training had several objectives. First, training was instituted in order to minimize the amount of learning that would occur once the actual work began. Second, since certain aspects of any interaction are unobserved in the data, the training sought to homogenize these interactions such that

\footnotetext{
${ }^{24}$ In particular, if post-Christmas sales were inventory-related, we would have expected firms to agree to grant discounts more frequently post-Christmas. We shall return to this question in Section 4.
} 
unobserved, non-random impressions or language used by the auditors would be minimized. Nevertheless, we control for auditor identity in our empirical analysis. The written instructions provided to the auditors prior to data collection may be found in Figure B.1.

Each assignment required the auditor to find a product for which he or she could express credible interest within a given price range. That is, for each store there were three distinct price ranges assigned. The ranges were calculated prior to issuing the bargaining assignments using the lowest and second highest prices observed at each store. For each assignment, auditors were given a store name, address, the nature of the products sold at the store (e.g. clothing) in order to prevent auditor errors, the posted price range within which they should find a product, and the date range on which they should visit the store. If an auditor could not easily find a product in the price range assigned, they were asked to find a price that was as close as possible to the range. Unfortunately, resource limitations prevented us from purchasing products if a discount was granted. For this project, we would have needed to spend approximately 73,010 EUR, recalling that discounts in the amount of approximately 7,715 EUR were granted on products that totaled approximately $80,725 \mathrm{EUR}$ in posted price. In addition to the large expense associated with purchasing products, it also would have been impossible to know which products would be discounted a priori, and therefore it would have been challenging to estimate an appropriate budget in such a case.

In a study such as this, not only are auditors assigned to collect observations, the outcome of their observations is partially dependent upon their own behavior. It follows that the "human element" is a non-trivial issue in our study. We therefore examine the behavior of the auditors in Appendix B. In Section B.1 we examine whether auditors deliberately targeted products at one end or another of the assigned price range and whether auditors deliberately targeted or avoided sale items. In Section B.2 we provide checks of the credibility of the outcomes reported by the auditors. In addition to these checks, we also note that measures were put in place in order to minimize the possibility that auditors fabricated their results. That is, in order to prevent auditors from sharing their results during the project, auditors were not told the names of the other students who were hired nor were their names displayed on group e-mails. In addition, auditors were informed that two additional auditors would visit the same store in order to implicitly remind them that the store's bargaining practices would also be documented by other individuals. Other analyses in Appendix B include examination of the effect of the first auditor visit on subsequent visits to the same store (Section B.3), a discussion of observation assignments that were not performed and errors in the observations recorded by auditors (Section B.4), and an analysis of how auditor performance varied over time (Section B.5). 


\section{Empirical analysis}

\subsection{Primary variables of interest}

The principal objective of our empirical analysis is to analyze the firm-side factors that influence the likelihood that a discount will be granted upon request. For identification purposes, it is therefore helpful that a small percentage of consumers (approximately $6 \%$ according to our previously-cited survey) ask for discounts because it is unlikely that a firm accounts for consumers who bargain when making posted-price decisions or when making decisions regarding the way in which it organizes itself, as noted earlier. Below we discuss the price and firm characteristics that we examine in our empirical study.

\subsubsection{Price $(p)$}

Both the list price and the posted price may serve as proxies for margins. First, for items that are not on sale, if it is the case that marginal costs and absolute price-cost margins are positively correlated in the cross-section of product markets that we observe, then price levels may provide an indication regarding margin size. Informally speaking, while it is certainly plausible that margins decrease as cost increases for a particular good, it would be unreasonable to expect this to hold true given the type of large, diverse cross-section of products that we observe, as this would imply that 1,000 EUR items typically have smaller absolute margins than 30 EUR items (whose margins may be no greater than 30 EUR). Second, for items that are on sale, the amount of a sale may also be informative about the margin. In principle, the relationship between sale amount and propensity to bargain may be positive or negative, but we expect a negative relationship. This is because most plausible explanations for sales in our dataset are price reductions due to (i) demand shocks, (ii) price randomization or (iii) inter-temporal price discrimination.

Summary statistics In Table 2 we report summary statistics related to price, sales, and discounts. The posted price is the price that the consumer would pay without explicitly asking for a discount. If the product is on sale, the posted price will be below the list price. Otherwise, the posted price is identical to the list price. Note that the maximum list price of 5,900 EUR was recorded for a carpet, which was associated with the maximum sale amount and sale percentage of 5,240 EUR and 89\%, respectively. The next highest list price was 1,299 EUR. Removing this observation has very little effect on our results. The third and fourth row of Table 2 report summary statistics of discounts granted due to bargaining; these cases are conditional on a discount being granted and are calculated off of the posted price (after any sale). One may infer from the table that 303 of 751 observations entailed a discount being granted due to bargaining and that 169 of 751 (about 22\%) items in the data were on sale.

Figure 1 illustrates the distribution of discounts in absolute and relative size. There were no discounts granted on approximately 60 percent of the observations, as can be seen in Figures 
Table 2: Summary price, sale, and discount statistics

$\begin{array}{lcccccc}\text { Variable } & \text { Mean } & \text { St. Dev. } & \text { Median } & \text { Min } & \text { Max } & \text { Obs } \\ \text { List price } & 237.133 & 302.48 & 149 & 30 & 5,900 & 751 \\ \text { Posted price (after any sale) } & 212.405 & 204.52 & 135 & 30 & 999.99 & 751 \\ \text { Sale amount (off of list price) } & 109.884 & 411.653 & 45 & 5 & 5,240 & 169 \\ \text { Sale percentage } & 0.306 & 0.147 & 0.3 & 0.034 & 0.888 & 169 \\ \text { Discount amount (off of posted price) } & 25.464 & 29.286 & 15 & 1 & 180 & 303 \\ \text { Discount percentage } & 0.098 & 0.066 & 0.098 & 0.008 & 0.407 & 303\end{array}$

1(a) and 1(c). Furthermore, note that Figure 1(b) only uses strictly positive discounts as the horizontal axis measures the log of discount amounts. In Figure 1(c), horizontal lines were added to show the relatively higher frequency of 3 percent, 5 percent, and 10 percent discounts. Figures C.1(a)-(b) illustrate the distribution of list prices observed in absolute and relative sizes, and Figures C.1(c)-(d) do the same for posted prices (after any sale reductions).

Figure 1: Distribution of discounts
(a) Discount amount
(b) $\ln$ (discount amount)
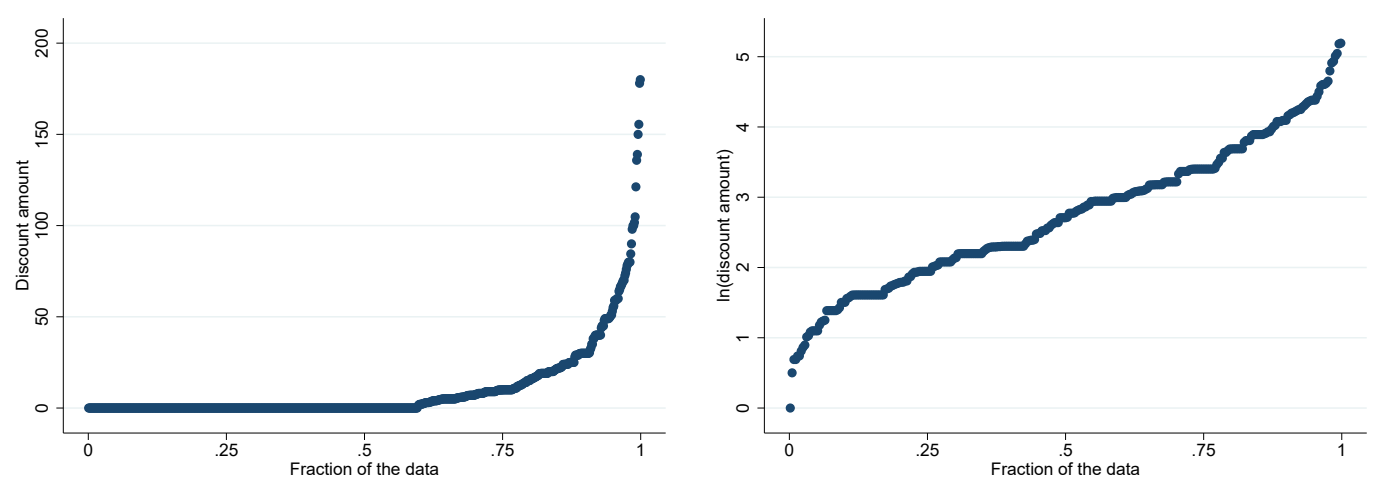

(c) Discount percentage

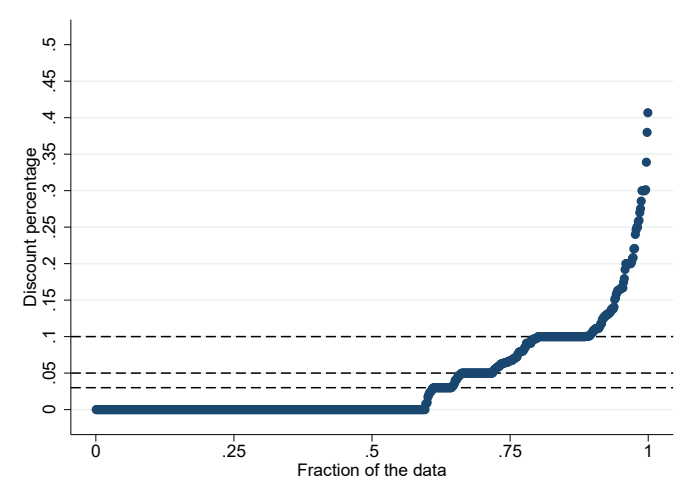

\subsubsection{The clerk's assessment of the customer $(\lambda)$}

For reasons discussed in Section 2.3, we tie the theoretical parameter $\lambda$ to our empirical observation of firm scale using the following store-specific empirical measures (summary statistics 
are provided in Table 5):

- Number of stores. The principle manner in which we define a firm's scale is according to the number of stores owned by the same firm. We will typically classify a firm owning up to five stores as small-scale and all other firms as large scale, although our results are robust to alternative thresholds as well. Drawing upon our discussion in Section 2.1, we presume that increases in employee monitoring costs outpace increases in firm scale.

- Domestic vs. multinational. As an alternative measure of a firm's scale, we also observe whether the firm is multinational in scope. We define a store as multinational either if its owner owns the same store outside of Austria or if it is a franchise store whose franchisor is a multinational firm. We expect that a multinational firm's decisions regarding the composition of its salesforce will be similar to large-scale firms even in cases when these two firm classifications do not overlap with one another.

- Walking seconds. An additional firm-side characteristic that we observe is the physical size of the store, as measured in the number of seconds required to walk once through the entire store. It may be reasonable to suppose that physically small stores are more likely to feature salespeople that are more adept or motivated to properly evaluate a consumer's valuation for a good.

- Number of employees. Finally, in most environments in which some customer service is provided, it is likely that the number of employees is endogenously chosen according to the number of customers in the store; for example, stores featuring only one or two employees typically serve relatively few customers at a given point in time. ${ }^{25}$ Such decisions are often related to a firm's scale. Several days prior to the bargaining interactions, the number of employees at each store was recorded during the information gathering stage. The advantage of recording these observations separately from the bargaining observations is that a given bargaining observation was not burdened by an excessive amount of data collection, and therefore an auditor was allowed to focus on selecting a product of interest, asking for a discount from a salesperson, and recording information related to the interaction. The downside of this approach is that the number of employees at a store may have been different several days prior to the bargaining interactions relative to the day on which the bargaining interaction took place.

The nature of the discounts offered serves as interesting evidence of how small-scale firms are organized differently from large-scale firms. In principle, a discount may be offered as a

\footnotetext{
${ }^{25}$ We should note that computing employee-customer ratios using our measure of customers observed is slightly problematic given the potential variation in customers observed during the information gathering stage relative to the bargaining stage. This is particularly true for observations in which there are several employees and a small number of customers observed. An additional possibility would be to construct a variable that indicates the difference between the number of employees and number of customers observed; however such a variable suffers from the drawback that a given difference at a store with a small number of employees and customers would be treated in the same manner as the same difference at a store with a larger number of employees and customers.
} 
round percentage (e.g., 3\%, 5\%, 10\%) or in a euro amount that clearly would not have been offered by the salesperson as a percentage. ${ }^{26}$ Table 3 illustrates how large-scale firms (more than five stores) offer a substantially higher ratio of discounts in round percentage terms than small-scale firms (up to five stores). This is informative for our purposes because it provides support for the notion that salespeople at large-scale firms are less likely to be given discretion to assess a haggler's true valuation for a good.

Table 4 lists all of the multinational stores in our dataset and the incidence with which a discount was granted at each firm. Whereas the names of domestic firms may not carry much meaning for readers outside of Austria, the recognizable names of many of the multinational firms should assist the reader to understand the types of large-scale firms that were observed in our study. ${ }^{27}$

Table 3: Count of discounts offered in round percentages: Small-scale vs. large-scale firms

$$
\begin{aligned}
& \text { Small-scale firms }(\leq 5 \text { stores }) \\
& \text { Round percentage Total \% of total }
\end{aligned}
$$

Integer posted price

Non-integer posted price

Total

$\begin{array}{ccc}93 & 219 & 42.5 \% \\ 25 & 37 & 67.6 \% \\ 118 & 256 & 46.1 \%\end{array}$

\author{
Large-scale firms (> 5 stores) \\ Round percentage Total \% of total
}

$\begin{array}{lll}23 & 33 & 69.7 \% \\ 12 & 14 & 85.7 \% \\ 35 & 47 & 74.5 \%\end{array}$

\subsubsection{The cost of bargaining $(b)$}

We view the number of customers in the store as a proxy for the firm's cost of bargaining. Like our observations of the number of employees at a store, the number of customers who entered each store during a three minute period was observed approximately one week before the bargaining observations commenced, and the same benefits and drawbacks of observing the number of employees at a different time than the bargaining interactions apply to this variable as well. Our primary interest in observing the number of customers that enter in a three minute period was to distinguish between stores that were observed to be empty with stores that were observed with customers. In particular, the cost associated with granting an individualized discount is low when no other customers are present in the store. According to Table 5, no customers were observed at nearly half of the stores surveyed.

\subsubsection{Other variables of interest}

We also include the following controls in our analysis which may influence a firm's bargaining behavior but for which predictions are less clear. Summary statistics for store-specific variables are provided in Table 5.

\footnotetext{
${ }^{26}$ For purposes of Table 3, we classify a discount as a round percentage if the percentage itself is an integer. Of course, there may have been a small number of observations in which a discount was quoted by the salesperson in euros which coincidentally also can be computed as a round percentage.

${ }^{27}$ Data regarding a firm's scale (the number of stores owned by the same firm) and its multinational status were verified via subscription to the Aurelia database offered by Bureau Van Dijk and via information provided by firm websites. When firm-scale and multinational status could not be confirmed via either of these two sources of information, the authors called the stores in the dataset directly in order to retrieve this information.
} 
Table 4: Discounting behavior of multinational stores

\begin{tabular}{|c|c|}
\hline Granted a discount at least once & Incidence \\
\hline Bucherer & 2 of 2 obs \\
\hline Cadenza & 1 of 3 obs \\
\hline Colli & 3 of 3 obs \\
\hline Dorotheum & 2 of 3 obs \\
\hline Douglas & 2 of 3 obs \\
\hline EMI Music & 1 of 2 obs \\
\hline Fogal & 1 of 3 obs \\
\hline Freytag\&Berndt & 2 of 3 obs \\
\hline Högl & 2 of 3 obs \\
\hline J\&L Lobmeyr & 2 of 2 obs \\
\hline Jacques Lemans (franchise store) & 3 of 3 obs \\
\hline Le Clou & 1 of 3 obs \\
\hline Levis (franchise store) & 1 of 3 obs \\
\hline Marionnaud & 1 of 3 obs \\
\hline Matratzen Concord & 3 of 3 obs \\
\hline Pandora (franchise store) & 1 of 3 obs \\
\hline Samsonite & 2 of 3 obs \\
\hline Saturn & 1 of 3 obs \\
\hline Sidestep & 2 of 3 obs \\
\hline Sport 2000 (franchise store) & 3 of 3 obs \\
\hline Stiefelkönig & 1 of 3 obs \\
\hline Tchibo & 1 of 3 obs \\
\hline Vans & 1 of 3 obs \\
\hline Wmf & 2 of 3 obs \\
\hline
\end{tabular}

\begin{tabular}{|c|c|}
\hline Never granted a discount & \\
\hline Aldo (franchise store) & \\
\hline Bonita & \\
\hline Boss & \\
\hline Butlers & \\
\hline Camper & \\
\hline Casa (franchise store) & \\
\hline Comma & \\
\hline Cos & \\
\hline Desigual & \\
\hline Diesel & \\
\hline Energie & \\
\hline Escada & \\
\hline Esprit & \\
\hline Footlocker & \\
\hline Fossil & \\
\hline Gabor & \\
\hline Georges Rech & \\
\hline Geox & \\
\hline Gerry Weber & \\
\hline Gloriette & \\
\hline Grüne Erde & \\
\hline G-Star (franchise store) & \\
\hline Gucci & \\
\hline $\mathrm{H} \& \mathrm{M}$ & \\
\hline Hallhuber & \\
\hline Humanic & \\
\hline Jack Wolfskin & \\
\hline Jack Jones & \\
\hline Joseph Ribkoff (franchise store) & \\
\hline Kare (franchise store) & \\
\hline Lacoste & \\
\hline Mango & \\
\hline Meblik Kids & \\
\hline Moncler & \\
\hline Mont blanc & \\
\hline Müller & \\
\hline Nespresso & \\
\hline Peak Performance & \\
\hline Pearle & \\
\hline Puma & \\
\hline S. Oliver & \\
\hline Salamander & \\
\hline Sisley (franchise store) & \\
\hline Sports Experts & \\
\hline Stefanel & \\
\hline Swarovski & \\
\hline Swatch & \\
\hline Tom Tailor & \\
\hline Triumph & \\
\hline Weltbild & \\
\hline Wolford & \\
\hline Zara & \\
\hline
\end{tabular}

Note: The designation as a franchise store was determined based on a telephone conversation with at least one salesperson at each of the above stores. As noted in Table 4, observations at multinational stores account for 219 of 751 observations overall. 


\section{Store-specific variables}

- Store type. In our analysis we classify observations into one of five categories: clothing, shoes/leather goods, jewelry, household, and other. We constructed these store category designations for each store in the absence of any preferable, more objective available designation. We further divide each store category into two subcategories: low-priced stores within a category and high-priced stores within a category. We classify the price level of a store within a category according to the second highest price observed at that store. One advantage of including variables that classify stores into categories is that such variables may capture crude differences in competition, which are otherwise very difficult to measure given the heterogeneity of products in the dataset. Competition reduces margins in most theoretical models of firm behavior, and therefore to the extent that two products share the same price but a product for which more competition exists has a higher marginal cost, store category indicator variables will seek to control for differences in margins across industries. ${ }^{28}$ Note that we are somewhat less interested in the coefficient estimates of these variables per se than we are in controlling for factors that may result in mismeasurement of the price variable coefficient estimates.

- Geographic area. We also control for a store's location in one of the four geographic areas introduced in Section 3: the 1st district, the 2nd and 20th districts, the 18th and 19th districts, and the 6th and 7th districts.

\section{Observation-specific variables}

- Salesperson gender and age. In his survey of several thousand employees throughout Western Europe, Ortega (2009) finds that female employees are given less discretion than male employees. Along these lines, it is both reasonable and interesting to investigate whether salesperson gender and age influence the likelihood of receiving a discount, controlling for other firm-side factors. These characteristics were recorded by the auditor based on the auditor's visual impression of the salesperson immediately following each bargaining observation.

- Time period. As discussed in Section 3, we control for whether the bargaining interaction took place during the period before Christmas or after Christmas.

- Auditor identity. We control for auditor identity via the inclusion of auditor fixed effects.

\subsection{The empirical model}

Two primary outcomes were recorded immediately following every bargaining attempt - whether or not a firm granted a discount for a particular product, and if a discount was granted, the

\footnotetext{
${ }^{28}$ Increased competition would imply a lower $p$ and in turn a smaller absolute margin in our theoretical monopoly model.
} 
Table 5: Summary statistics of store-specific variables

Variable

Unique stores in the dataset

Observations

Number of stores worldwide

$\begin{array}{cc}1 & 130 \\ 2 & 30 \\ 3 & 13 \\ 4 & 1 \\ 5 & 5 \\ 6 & 5 \\ 7 & 5 \\ 8 & 5 \\ 10-15 & 2 \\ >15 & 7\end{array}$

130

30

85

$13-36$

$10-30$

5

5

5

206

$6-17$

$74 \quad 213$

Domestic/Multinational

Domestic

Multinational

Geographic area

1 st district

2nd and 20th districts

18th and 19th districts

57

137

6th and 7th districts

Employees

1

117

293

2

67

187

3

30

87

4

61

5

22

24

$>5$

99

Number of customers observed

$$
0
$$

1

349

2

3

26

72

56

4

20

12

5

6

6-10

17

$>10$

26

73

18

52

Store type

Clothing

96

270

Shoes/Leather goods

Jewelry

33

94

Household

36

96

Other

Walking seconds

Up to 30 seconds 
size of the discount. The first outcome is essentially a participation decision - whether or not to grant a discount, and the second outcome is an amount decision that is bounded below at zero. Since our theoretical predictions do not imply that every variable of interest will influence the participation decision and the amount decision in the same direction, we consider a flexible model whereby separate mechanisms are allowed to determine the participation decision and the amount decision.

Let $d$ be a binary variable that indicates whether the observed discount size $z$ is zero or strictly positive, and let $z^{*}$ be a nonnegative, continuously distributed latent variable that represents the size of the discount that the salesperson will offer. Then we may write:

$$
z=d z^{*}
$$

When a discount is strictly positive, $d=1$ and $z=z^{*}$; otherwise $d=z=0$. First, let us suppose that $d$ and $z^{*}$ are independent conditional on a set of explanatory variables. We model the participation decision in terms of the probit model, where we denote $r$ as a vector of covariates affecting whether or not a particular firm will choose to bargain for a particular product if $\omega=r \alpha+v>0$ :

$$
P(d=1 \mid r)=\Phi(r \alpha)
$$

Note that the model cannot predict negative outcomes for $z$ because the support of $z^{*}$ is $(0, \infty)$. One possibility is to define the amount equation as:

$$
z^{*}=x \beta+u
$$

where $u$ given $x$ follows a truncated normal distribution with lower truncation point $-x \beta$. This equation, together with (2), is commonly referred to as the truncated normal hurdle (TNH) model and was first proposed by Cragg (1971). Another possibility is to define

$$
z^{*}=e^{(x \beta+u)}
$$

where $u$ given $x$ follows a normal distribution with mean zero and variance $\sigma^{2}$. Also proposed by Cragg (1971), this equation together with (2) is commonly referred to as the lognormal hurdle (LNH) model. Here, we may express $z$ as:

$$
z=d z^{*}=1[r \alpha+v>0] e^{(x \beta+u)}
$$

where $v$ is unobservable with a standard normal distribution, $u$ and $v$ are independent, and $(u, v)$ is independent of $x$ with a bivariate normal distribution. In this case, due to our previous assumption on the distribution of $u$, we may say that $z^{*}=e^{(x \beta+u)}$ has a lognormal distribution and $z$ conditional on $(x, z>0)$ has a lognormal distribution as well because we assume that the errors of the participation and amount equations are independent of each other. Whether the amount equation is modeled according to (3) or (4), the participation equation and the amount equation may be modeled independently from one another. 
One may also relax the assumption that $\operatorname{Cov}(u, v)=0$ and modify the lognormal hurdle model in order to obtain the Exponential Type II Tobit (ET2T) model. Heckman (1976) originally presented this two-step method for purposes of dealing with sample selection. When implementing the ET2T model, one may not utilize (3) because negative outcomes on the dependent variable in the amount equation are allowed; this would be a particular concern if $\operatorname{Corr}(u, v)=\rho$ is estimated to be negative. Therefore one may only apply the Type II model to an amount equation in which $\ln (z)$ is the dependent variable (as is the case when employing (4)). The literature has noted that the ET2T model carries a potential risk of poor identification, particularly if $r \equiv x$. In contrast, there are no analogous concerns associated with including all covariates in both the participation equation and the amount equation in either the TNH model or the LNH model. ${ }^{29}$

\subsection{Empirical results}

We specify the participation equation using (2). The right-hand-side variables of the participation equation, to be discussed in more detail below, are listed in Tables 6 and 7. We also include three interactions in the participation equation: list price with firm scale, firm scale with sale size, and sale size with observation period (pre-Christmas or post-Christmas). In our forthcoming discussion of the results we shall explain our interest in these interactions. The amount equations reported in the paper contain all of the variables contained in the participation equation but without these three interactions, primarily for reasons related to sample size.

We analyze the participation and amount equations using the TNH model, the LNH model, and ET2T model. Because these models are non-nested, we apply Vuong's (1989) test to check whether the difference in log-likelihoods between the TNH model and the LNH model is statistically significant. The test finds that the average difference in the log likelihood between the LNH model and the TNH model is 0.163 and statistically significant at the .01 level. Therefore, we have strong evidence that the TNH model is inappropriate for our empirical application. It is also interesting to note that the TNH model fits better than a Type I Tobit model using discount amount as the dependent variable, further evidence that a flexible twopart specification is most appropriate in our setting. ${ }^{30}$

We implement the ET2T model once with all of the variables included in the amount equation in the LNH model and once excluding variables from the amount equation for which our theoretical predictions are less clear (in which case we do not reject the null hypothesis that $\rho=0$ at the .05 level). ${ }^{31}$ Our estimates of interest in both specifications are qualitatively similar to those in the LNH model. Given the similarity of the LNH and ET2T results and given

\footnotetext{
${ }^{29}$ For a thorough treatment of two-part models and Type II Tobit for corner solutions, see Wooldridge (2010).

${ }^{30}$ Applying a $\chi^{2}$ test with a number of restrictions equal to the number of variables in the Tobit model, the LR statistic is $2(-L L($ Tobit $)+L L(T N H))=2(1649-1523)=252$, which is statistically significant. Therefore the TNH model is a superior fit than the Type I Tobit model.

${ }^{31}$ The amount equation of the parsimonious specification includes list price quartiles, sale size categories, firm scale in terms of number of stores and number of employees, and number of customers. Estimates obtained from the ET2T model are available from the authors upon request.
} 
the statistically significant difference in log likelihoods between the TNH and LNH models, we therefore only report our results associated with the LNH model in what follows.

\subsubsection{Discussion of empirical results}

Prices. Our results indicate that discounts are more likely to be granted for higher priced products. In Table 6 we divide prices into quartiles; this allows for a certain degree of flexibility in estimating the relationship between price and bargaining propensity. As discussed above, if absolute margins do in fact increase with costs in the cross-section of product markets that we observe, this empirical finding would be consistent with the existence of such a relationship. In Table 7 we report three alternate specifications in which we include list price terciles, the logarithm of list price, and posted price quartiles. When using the logarithm of list price instead of list price quartiles, the elasticity of discount size with respect to list price is estimated to be nearly unitary (as shown in the fourth column of Table 7). Therefore the percentage discount given by a firm is predicted to be nearly constant at all price levels in the data. This finding in the amount equation is consistent with the participation equation result that discount probability increases with price, noting that only an increasing relationship between costs and absolute margins would allow for the percentage discount to remain constant as price increases.

We categorize sale items according to the absolute size of the sale. That is, we distinguish between 85 observations for which the sale size is up to 45 EUR (to which we refer as small sale size items) from 84 observations for which the sale size is greater than 45 EUR (to which we refer as large sale size items). We find that both categories of sale items are significantly less likely to earn a discount than non-sale items by a substantial difference. Such a finding would be consistent with the hypothesis that for products with the same list price, absolute margins are lower for sale products. However, we do not find a significant difference in probability of earning a discount between the two categories of sale items.

Given the period for which we collected data, one question that arises is whether sales immediately after Christmas reflect firms' desire to clear inventory. If one assumes that sales that occur two to three weeks prior to Christmas do not reflect a desire to clear inventory, we may get a sense of whether sales during the period after Christmas are inventory-related by examining whether firms were more likely to bargain on sale items after Christmas. Using the specification reported in the first column of Table 6, Figure 2(a) shows that the predicted probability of receiving a discount after Christmas is not higher than before Christmas for non-sale items or sale items. It is more likely the case that inventory-related clearance sales begin in earnest as end-of-the-season sales later in January, continuing into February.

Unfortunately, we only observed 26 sale items for which a discount was granted, and therefore our ability to draw conclusions regarding the relationship between sale size and discount size is limited. Items that we categorize as sold at a small sale size are granted discounts that are smaller in magnitude (with weak statistical significance) than items that are not on sale, which is consistent with our finding from the participation equation. However, we do not find a statistically significant difference in discount amounts given to large sale size items relative 
Table 6: Average partial effects in the participation and amount equations: Alternative firmscale variables

\begin{tabular}{|c|c|c|c|c|c|c|c|c|}
\hline List price: 2nd quartile & \begin{tabular}{|c} 
Part Eq \\
0.071 \\
$(0.039)$
\end{tabular} & $\begin{array}{c}\text { Amt Eq } \\
0.525 \\
(0.109)\end{array}$ & $\begin{array}{l}\text { Part Eq } \\
0.063 \\
(0.039)\end{array}$ & $\begin{array}{c}\text { Amt Eq } \\
0.525 \\
(0.109)\end{array}$ & $\begin{array}{c}\text { Part Eq } \\
\\
0.062 \\
(0.039)\end{array}$ & $\begin{array}{l}\text { Amt Eq } \\
0.517 \\
(0.108)\end{array}$ & $\begin{array}{c}\text { Part Eq } \\
\\
0.075 \\
(0.037)\end{array}$ & $\begin{array}{c}\text { Amt Eq } \\
0.528 \\
(0.108)\end{array}$ \\
\hline List price: 3rd quartile & $\begin{array}{c}0.182 \\
(0.044)\end{array}$ & $\begin{array}{c}1.139 \\
(0.126)\end{array}$ & $\begin{array}{c}0.174 \\
(0.045)\end{array}$ & $\begin{array}{c}1.135 \\
(0.126)\end{array}$ & $\begin{array}{c}0.18 \\
(0.044)\end{array}$ & $\begin{array}{c}1.134 \\
(0.125)\end{array}$ & $\begin{array}{c}0.188 \\
(0.044)\end{array}$ & $\begin{array}{c}1.147 \\
(0.125)\end{array}$ \\
\hline List price: 4 th quartile & $\begin{array}{c}0.192 \\
(0.05)\end{array}$ & $\begin{array}{c}1.86 \\
(0.132)\end{array}$ & $\begin{array}{c}0.188 \\
(0.053)\end{array}$ & $\begin{array}{c}1.858 \\
(0.132)\end{array}$ & $\begin{array}{c}0.202 \\
(0.052)\end{array}$ & $\begin{array}{c}1.847 \\
(0.131)\end{array}$ & $\begin{array}{l}0.203 \\
(0.05)\end{array}$ & $\begin{array}{c}1.863 \\
(0.131)\end{array}$ \\
\hline Small sale item & $\begin{array}{c}-0.274 \\
(0.05)\end{array}$ & $\begin{array}{l}-0.446 \\
(0.243)\end{array}$ & $\begin{array}{l}-0.287 \\
(0.048)\end{array}$ & $\begin{array}{l}-0.451 \\
(0.241)\end{array}$ & $\begin{array}{c}-0.266 \\
(0.049)\end{array}$ & $\begin{array}{c}-0.456 \\
(0.248)\end{array}$ & $\begin{array}{c}-0.282 \\
(0.048)\end{array}$ & $\begin{array}{c}-0.447 \\
(0.242)\end{array}$ \\
\hline Large sale item & $\begin{array}{c}-0.295 \\
(0.046)\end{array}$ & $\begin{array}{c}0.15 \\
(0.216)\end{array}$ & $\begin{array}{c}-0.296 \\
(0.046)\end{array}$ & $\begin{array}{c}0.132 \\
(0.205)\end{array}$ & $\begin{array}{c}-0.299 \\
(0.046)\end{array}$ & $\begin{array}{c}0.139 \\
(0.216)\end{array}$ & $\begin{array}{c}-0.302 \\
(0.043)\end{array}$ & $\begin{array}{c}0.152 \\
(0.216)\end{array}$ \\
\hline More than five stores & $\begin{array}{c}-0.185 \\
(0.052)\end{array}$ & $\begin{array}{c}0.033 \\
(0.137)\end{array}$ & & & & & & \\
\hline Multinational firm & & & $\begin{array}{c}-0.196 \\
(0.055)\end{array}$ & $\begin{array}{c}0.053 \\
(0.165)\end{array}$ & & & & \\
\hline Walking seconds $>30$ & & & & & $\begin{array}{c}-0.083 \\
(0.055)\end{array}$ & $\begin{array}{c}-0.105 \\
(0.117)\end{array}$ & & \\
\hline Between 4-15 stores & & & & & & & $\begin{array}{c}-0.105 \\
(0.062)\end{array}$ & $\begin{array}{c}-0.083 \\
(0.133)\end{array}$ \\
\hline More than 15 stores & & & & & & & $\begin{array}{c}-0.257 \\
(0.052)\end{array}$ & $\begin{array}{c}-0.021 \\
(0.174)\end{array}$ \\
\hline Dec 27 - Jan 4 & $\begin{array}{c}-0.059 \\
(0.027)\end{array}$ & $\begin{array}{c}0.098 \\
(0.077)\end{array}$ & $\begin{array}{c}-0.065 \\
(0.027)\end{array}$ & $\begin{array}{c}0.101 \\
(0.076)\end{array}$ & $\begin{array}{c}-0.054 \\
(0.027)\end{array}$ & $\begin{array}{c}0.094 \\
(0.075)\end{array}$ & $\begin{array}{c}-0.058 \\
(0.027)\end{array}$ & $\begin{array}{c}0.096 \\
(0.077)\end{array}$ \\
\hline Female salesperson & $\begin{array}{l}-0.066 \\
(0.039)\end{array}$ & $\begin{array}{l}-0.132 \\
(0.096)\end{array}$ & $\begin{array}{c}-0.098 \\
(0.038)\end{array}$ & $\begin{array}{c}-0.133 \\
(0.098)\end{array}$ & $\begin{array}{c}-0.09 \\
(0.039)\end{array}$ & $\begin{array}{c}-0.143 \\
(0.098)\end{array}$ & $\begin{array}{c}-0.055 \\
(0.038)\end{array}$ & $\begin{array}{c}-0.13 \\
(0.097)\end{array}$ \\
\hline One customer & $\begin{array}{l}-0.057 \\
(0.054)\end{array}$ & $\begin{array}{c}-0.27 \\
(0.135)\end{array}$ & $\begin{array}{c}-0.101 \\
(0.05)\end{array}$ & $\begin{array}{c}-0.269 \\
(0.138)\end{array}$ & $\begin{array}{c}-0.078 \\
(0.055)\end{array}$ & $\begin{array}{c}-0.254 \\
(0.138)\end{array}$ & $\begin{array}{l}-0.056 \\
(0.051)\end{array}$ & $\begin{array}{c}-0.265 \\
(0.137)\end{array}$ \\
\hline Two customers & $\begin{array}{c}-0.086 \\
(0.061)\end{array}$ & $\begin{array}{c}-0.276 \\
(0.161)\end{array}$ & $\begin{array}{c}-0.091 \\
(0.057)\end{array}$ & $\begin{array}{c}-0.271 \\
(0.160)\end{array}$ & $\begin{array}{c}-0.055 \\
(0.067)\end{array}$ & $\begin{array}{c}-0.236 \\
(0.169)\end{array}$ & $\begin{array}{c}-0.089 \\
(0.057)\end{array}$ & $\begin{array}{c}-0.281 \\
(0.161)\end{array}$ \\
\hline Three or more customers & $\begin{array}{l}-0.067 \\
(0.071)\end{array}$ & $\begin{array}{c}-0.361 \\
(0.174)\end{array}$ & $\begin{array}{c}-0.038 \\
(0.067)\end{array}$ & $\begin{array}{c}-0.367 \\
(0.175)\end{array}$ & $\begin{array}{c}-0.08 \\
(0.071)\end{array}$ & $\begin{array}{c}-0.339 \\
(0.176)\end{array}$ & $\begin{array}{c}-0.052 \\
(0.066)\end{array}$ & $\begin{array}{c}-0.371 \\
(0.178)\end{array}$ \\
\hline Two employees & $\begin{array}{l}-0.027 \\
(0.051)\end{array}$ & $\begin{array}{c}-0.003 \\
(0.108)\end{array}$ & $\begin{array}{c}-0.037 \\
(0.05)\end{array}$ & $\begin{array}{c}-0.002 \\
(0.108)\end{array}$ & $\begin{array}{c}-0.024 \\
(0.052)\end{array}$ & $\begin{array}{c}0.01 \\
(0.107)\end{array}$ & $\begin{array}{c}-0.038 \\
(0.048)\end{array}$ & $\begin{array}{c}0.001 \\
(0.107)\end{array}$ \\
\hline Three employees & $\begin{array}{l}-0.108 \\
(0.068)\end{array}$ & $\begin{array}{c}-0.164 \\
(0.166)\end{array}$ & $\begin{array}{c}-0.106 \\
(0.067)\end{array}$ & $\begin{array}{c}-0.17 \\
(0.171)\end{array}$ & $\begin{array}{c}-0.106 \\
(0.074)\end{array}$ & $\begin{array}{c}-0.132 \\
(0.172)\end{array}$ & $\begin{array}{c}-0.104 \\
(0.069)\end{array}$ & $\begin{array}{c}-0.166 \\
(0.167)\end{array}$ \\
\hline Four or more employees & $\begin{array}{c}-0.178 \\
(0.076)\end{array}$ & $\begin{array}{c}0.124 \\
(0.199)\end{array}$ & $\begin{array}{c}-0.199 \\
(0.072)\end{array}$ & $\begin{array}{c}0.109 \\
(0.195)\end{array}$ & $\begin{array}{c}-0.193 \\
(0.079)\end{array}$ & $\begin{array}{c}0.166 \\
(0.2)\end{array}$ & $\begin{array}{c}-0.167 \\
(0.073)\end{array}$ & $\begin{array}{c}0.135 \\
(0.195)\end{array}$ \\
\hline $\begin{array}{l}\text { Geographic controls } \\
\text { Store category controls } \\
\text { Salesperson age controls } \\
\text { Auditor fixed effects }\end{array}$ & $\begin{array}{l}\mathrm{Y} \\
\mathrm{Y} \\
\mathrm{Y} \\
\mathrm{Y}\end{array}$ & $\begin{array}{l}\mathrm{Y} \\
\mathrm{Y} \\
\mathrm{Y} \\
\mathrm{Y}\end{array}$ & $\begin{array}{l}\mathrm{Y} \\
\mathrm{Y} \\
\mathrm{Y} \\
\mathrm{Y}\end{array}$ & $\begin{array}{l}Y \\
Y \\
Y \\
Y\end{array}$ & $\begin{array}{l}Y \\
Y \\
Y \\
Y\end{array}$ & $\begin{array}{l}\mathrm{Y} \\
\mathrm{Y} \\
\mathrm{Y} \\
\mathrm{Y}\end{array}$ & $\begin{array}{l}\mathrm{Y} \\
\mathrm{Y} \\
\mathrm{Y} \\
\mathrm{Y}\end{array}$ & $\begin{array}{l}\mathrm{Y} \\
\mathrm{Y} \\
\mathrm{Y} \\
\mathrm{Y}\end{array}$ \\
\hline Observations & 751 & 303 & 751 & 303 & 751 & 303 & 751 & 303 \\
\hline Log likelihood & \multicolumn{2}{|c|}{-1473.399} & \multicolumn{2}{|c|}{-1471.108} & \multicolumn{2}{|c|}{-1481.014} & \multicolumn{2}{|c|}{-1463.161} \\
\hline
\end{tabular}

Note: Default categories are 1st quartile, non-sale items, firms with up to five stores, domestic firms, walking seconds $\leq 30$, firms with up to three stores, Dec 9 - Dec 14, male salesperson, no customers observed, and one employee observed. Standard errors are in parentheses. Standard errors in the participation and amount equations are clustered at the store level. 
Table 7: Average partial effects in the participation and amount equations: Alternative price variables

\begin{tabular}{|c|c|c|c|c|c|c|}
\hline & Part Eq & Amt Eq & Part Eq & Amt Eq & Part Eq & Amt Eq \\
\hline List price: 2 nd tercile & $\begin{array}{c}0.085 \\
(0.035)\end{array}$ & $\begin{array}{c}0.684 \\
(0.102)\end{array}$ & & & & \\
\hline List price: $3 r d$ tercile & $\begin{array}{c}0.183 \\
(0.045)\end{array}$ & $\begin{array}{c}1.603 \\
(0.111)\end{array}$ & & & & \\
\hline ln (list price) & & & $\begin{array}{c}0.093 \\
(0.022)\end{array}$ & $\begin{array}{c}0.91 \\
(0.054)\end{array}$ & & \\
\hline Posted price: 2nd quartile & & & & & $\begin{array}{l}0.025 \\
(0.04)\end{array}$ & $\begin{array}{c}0.491 \\
(0.120)\end{array}$ \\
\hline Posted price: 3rd quartile & & & & & $\begin{array}{c}0.152 \\
(0.045)\end{array}$ & $\begin{array}{c}1.05 \\
(0.124)\end{array}$ \\
\hline Posted price: 4th quartile & & & & & $\begin{array}{c}0.174 \\
(0.053)\end{array}$ & $\begin{array}{c}1.821 \\
(0.137)\end{array}$ \\
\hline Small sale item & $\begin{array}{c}-0.267 \\
(0.049)\end{array}$ & $\begin{array}{c}-0.469 \\
(0.263)\end{array}$ & $\begin{array}{c}-0.273 \\
(0.049)\end{array}$ & $\begin{array}{c}-0.532 \\
(0.237)\end{array}$ & $\begin{array}{l}-0.258 \\
(0.05)\end{array}$ & $\begin{array}{c}-0.288 \\
(0.255)\end{array}$ \\
\hline Large sale item & $\begin{array}{c}-0.285 \\
(0.047)\end{array}$ & $\begin{array}{c}0.021 \\
(0.219)\end{array}$ & $\begin{array}{c}-0.304 \\
(0.045)\end{array}$ & $\begin{array}{c}-0.028 \\
(0.181)\end{array}$ & $\begin{array}{c}-0.256 \\
(0.049)\end{array}$ & $\begin{array}{c}0.348 \\
(0.192)\end{array}$ \\
\hline More than five stores & $\begin{array}{l}-0.181 \\
(0.052)\end{array}$ & $\begin{array}{c}0.056 \\
(0.136)\end{array}$ & $\begin{array}{l}-0.184 \\
(0.051)\end{array}$ & $\begin{array}{c}-0.079 \\
(0.133)\end{array}$ & $\begin{array}{l}-0.182 \\
(0.052)\end{array}$ & $\begin{array}{c}-0.019 \\
(0.138)\end{array}$ \\
\hline Dec 27 - Jan 4 & $\begin{array}{c}-0.063 \\
(0.027)\end{array}$ & $\begin{array}{c}0.026 \\
(0.080)\end{array}$ & $\begin{array}{l}-0.058 \\
(0.027)\end{array}$ & $\begin{array}{c}0.085 \\
(0.070)\end{array}$ & $\begin{array}{l}-0.057 \\
(0.027)\end{array}$ & $\begin{array}{c}0.081 \\
(0.079)\end{array}$ \\
\hline Female salesperson & $\begin{array}{c}-0.066 \\
(0.039)\end{array}$ & $\begin{array}{c}-0.094 \\
(0.096)\end{array}$ & $\begin{array}{c}-0.062 \\
(0.039)\end{array}$ & $\begin{array}{c}-0.108 \\
(0.093)\end{array}$ & $\begin{array}{c}-0.064 \\
(0.039)\end{array}$ & $\begin{array}{c}-0.106 \\
(0.098)\end{array}$ \\
\hline One customer & $\begin{array}{c}-0.049 \\
(0.054)\end{array}$ & $\begin{array}{c}-0.158 \\
(0.139)\end{array}$ & $\begin{array}{c}-0.054 \\
(0.053)\end{array}$ & $\begin{array}{c}-0.217 \\
(0.125)\end{array}$ & $\begin{array}{c}-0.059 \\
(0.053)\end{array}$ & $\begin{array}{c}-0.278 \\
(0.133)\end{array}$ \\
\hline Two customers & $\begin{array}{l}-0.092 \\
(0.061)\end{array}$ & $\begin{array}{c}-0.322 \\
(0.162)\end{array}$ & $\begin{array}{l}-0.090 \\
(0.061)\end{array}$ & $\begin{array}{l}-0.338 \\
(0.156)\end{array}$ & $\begin{array}{c}-0.091 \\
(0.061)\end{array}$ & $\begin{array}{c}-0.304 \\
(0.166)\end{array}$ \\
\hline Three or more customers & $\begin{array}{c}-0.066 \\
(0.07)\end{array}$ & $\begin{array}{l}-0.362 \\
(0.177)\end{array}$ & $\begin{array}{l}-0.062 \\
(0.071)\end{array}$ & $\begin{array}{l}-0.362 \\
(0.172)\end{array}$ & $\begin{array}{c}-0.071 \\
(0.07)\end{array}$ & $\begin{array}{c}-0.428 \\
(0.170)\end{array}$ \\
\hline Two employees & $\begin{array}{c}-0.026 \\
(0.052)\end{array}$ & $\begin{array}{c}-0.011 \\
(0.108)\end{array}$ & $\begin{array}{c}-0.024 \\
(0.052)\end{array}$ & $\begin{array}{c}0.008 \\
(0.105)\end{array}$ & $\begin{array}{l}-0.027 \\
(0.052)\end{array}$ & $\begin{array}{c}0.042 \\
(0.112)\end{array}$ \\
\hline Three employees & $\begin{array}{c}-0.109 \\
(0.069)\end{array}$ & $\begin{array}{c}-0.136 \\
(0.166)\end{array}$ & $\begin{array}{l}-0.106 \\
(0.068)\end{array}$ & $\begin{array}{c}-0.17 \\
(0.152)\end{array}$ & $\begin{array}{c}-0.111 \\
(0.068)\end{array}$ & $\begin{array}{c}-0.171 \\
(0.169)\end{array}$ \\
\hline Four or more employees & $\begin{array}{l}-0.176 \\
(0.075)\end{array}$ & $\begin{array}{c}0.184 \\
(0.201)\end{array}$ & $\begin{array}{c}-0.18 \\
(0.076)\end{array}$ & $\begin{array}{c}0.101 \\
(0.194)\end{array}$ & $\begin{array}{l}-0.178 \\
(0.075)\end{array}$ & $\begin{array}{c}0.132 \\
(0.190)\end{array}$ \\
\hline $\begin{array}{l}\text { Geographic controls } \\
\text { Store category controls } \\
\text { Salesperson age controls } \\
\text { Auditor fixed effects }\end{array}$ & $\begin{array}{l}\mathrm{Y} \\
\mathrm{Y} \\
\mathrm{Y} \\
\mathrm{Y}\end{array}$ & $\begin{array}{l}\mathrm{Y} \\
\mathrm{Y} \\
\mathrm{Y} \\
\mathrm{Y}\end{array}$ & $\begin{array}{l}\mathrm{Y} \\
\mathrm{Y} \\
\mathrm{Y} \\
\mathrm{Y}\end{array}$ & $\begin{array}{l}\mathrm{Y} \\
\mathrm{Y} \\
\mathrm{Y} \\
\mathrm{Y}\end{array}$ & $\begin{array}{l}\mathrm{Y} \\
\mathrm{Y} \\
\mathrm{Y} \\
\mathrm{Y}\end{array}$ & $\begin{array}{l}\mathrm{Y} \\
\mathrm{Y} \\
\mathrm{Y} \\
\mathrm{Y}\end{array}$ \\
\hline Observations & 751 & 303 & 751 & 303 & 751 & 303 \\
\hline Log likelihood & \multicolumn{2}{|c|}{-1486.753} & \multicolumn{2}{|c|}{-1460.289} & \multicolumn{2}{|c|}{-1478.4} \\
\hline
\end{tabular}

Note: Default categories are 1st tercile (list), 1st quartile (posted), non-sale items, firms with up to five stores, Dec 9 - Dec 14, male salesperson, no customers observed, and one employee observed. Standard errors are in parentheses. Standard errors in the participation and amount equations are clustered at the store level. 
Figure 2: Predicted probability of a discount: Sale size and time period, list price quartile and firm scale, and sale size and firm scale

(a) Sale size category and time period

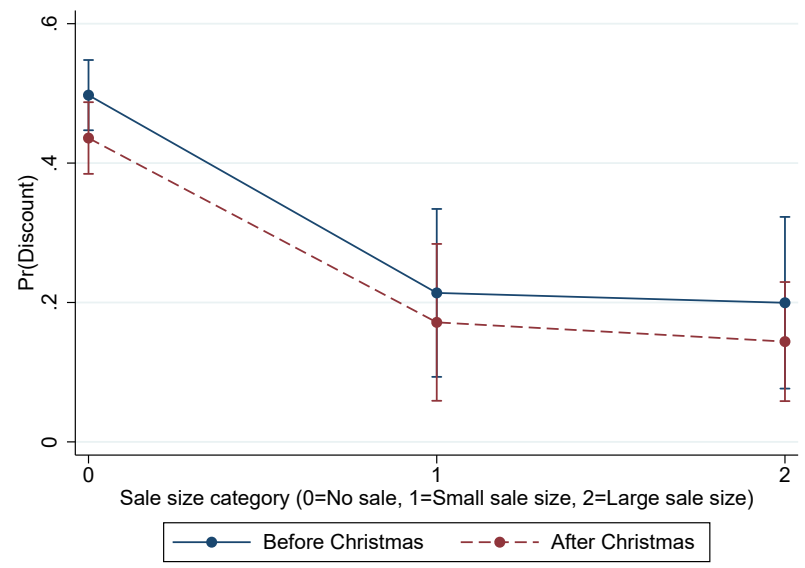

(b) List price quartile and firm scale

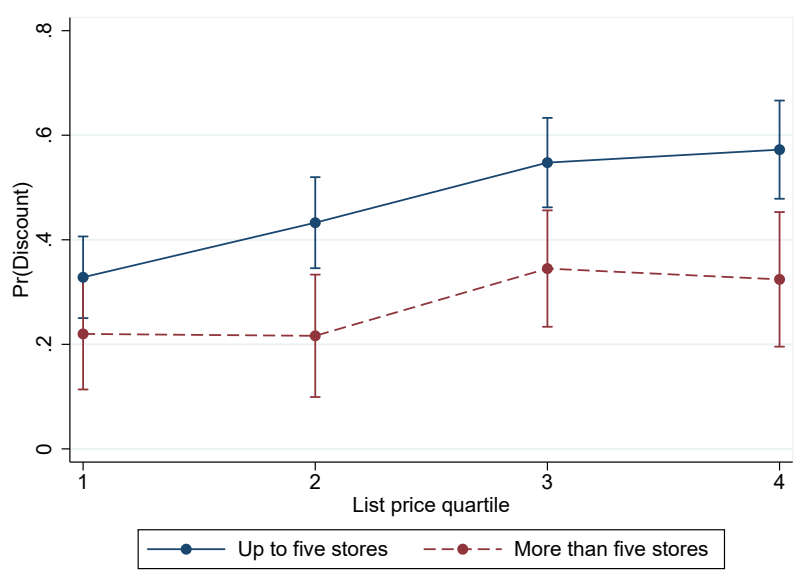

(c) Sale size category and firm scale

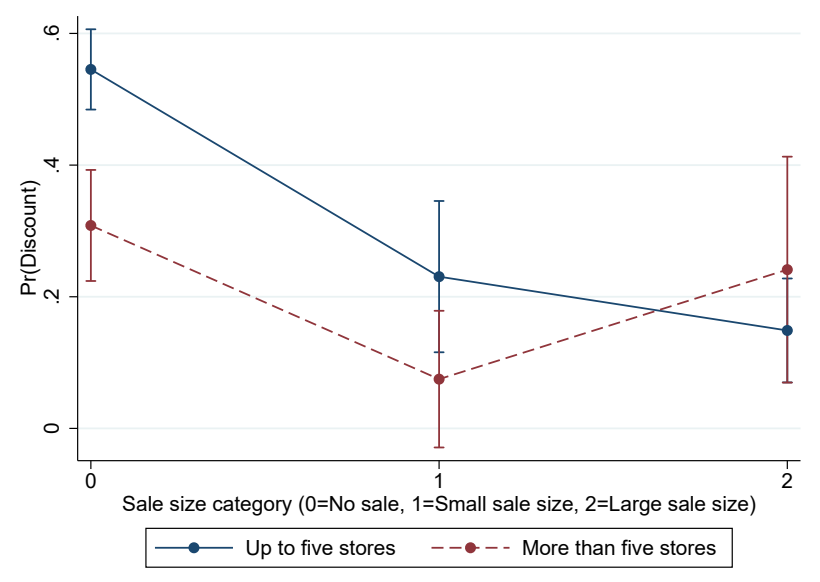

to non-sale items. One possible explanation for this finding is that these large sale size items comprise a small subset of items on inventory-related sales, however this is not entirely clear.

Firm scale. Our results indicate that discounts are significantly less likely to be granted at large-scale firms overall, and as seen in Table 6, this finding holds whether we categorize largescale firms as those with more than five stores, those which are multinational firms, or those with more than 15 stores. When categorizing stores according to their physical size as measured in walking seconds, we find that the effect of physical size on the probability of observing a discount granted is negative but statistically insignificant.

It is natural to draw a connection between firm-scale and the parameter $\lambda$ in our theoretical model. For previously cited reasons that follow from high per-employee monitoring costs at large-scale firms, salespeople at such firms are less likely to respond optimally (from the firm's standpoint) to a consumer's request for a discount. The firm, in turn, will take this into consideration when formulating its bargaining policy. It follows that we expect that discounts 
are more likely to be granted at small-scale stores.

Furthermore, our theory predicts that the firm's benefit from bargaining will be proportional to the price of the good, and increasingly so the more effectively the salesperson assesses the consumer's true valuation. Intuitively, when a salesperson evaluates a consumer's valuation well, the resulting extra profit will be larger in magnitude for higher-priced (higher-margin) goods because for such goods, reducing the price for hagglers is more likely to be profitable after the bargaining cost is paid. Therefore, we interact our price variable with our indicator for firm scale. We find that as the price increases, the difference in probabilities of obtaining a discount between small-scale stores and large-scale stores generally widens. This may be observed in Figure 2(b) and in Figures C.2 and C.3.

Given our theoretical prediction regarding the interaction between $\lambda$ and the product's absolute margin, we would be faced with an identification issue if margins tended to be larger for firms with a higher value of $\lambda$. However, it is not unreasonable to presume that margins of large-scale, multinational firms (those with a presumably low value of $\lambda$ ) are typically at least as large as those of smaller-scale firms. ${ }^{32}$ Intuitively, one would expect large-scale firms to have higher margins because their buying power should allow them to purchase their inventory at a lower marginal cost than their competitors, and these cost savings are not necessarily passed on to consumers. If this is the case, then our estimate of the difference of the effect of $\lambda$ across small-scale stores and large-scale stores would be conservatively low.

If one were to make a case for small scale firms differing from large scale firms in terms of their product line, then one may also attribute the lower probability of obtaining a discount to this difference. In particular, one could build a theoretical argument that firms with multiple vertically differentiated products would be able to cater to various consumer types to such a degree that their incentives to use bargaining to differentiate between consumers would be lower than for firms with a limited product line. However, it is not clear that the product lines of large scale firms in our study are deeper, and in fact one could also make a case for the opposite given that smaller firms tend to specialize. For this reason, it is useful that we have data regarding the physical size of a store, which may be an indicator of the depth of a store's product line. When controlling for the physical size of a store, our results are qualitatively similar.

An additional prediction from our theory is a second-order effect relating to the interaction between $\lambda$ and the size of a sale. That is, while any sale (for which absolute price-cost margins decrease) reduces the propensity to bargain, an increase in the amount of a sale reduces the propensity to bargain of small-scale firms (for whom $\lambda$ is presumably closer to one) by a larger amount than for large-scale firms. Therefore we would expect that small-scale firms' decreases in propensity to bargain will be more substantial than large-scale firms' decreases in propensity to bargain as the size of a sale increases. Drawing upon the results associated with the specification in the first column of Table 6, this may be observed in Figure 2(c) in which the slope of the line representing large firms that stretches from 0 to 1 on the $x$-axis is larger

\footnotetext{
${ }^{32}$ For example, see Kwoka (1979), Nooteboom (1982), and De Loecker and Warzynski (2012).
} 
than the slope of the line representing small firms over the same horizontal domain, and this is also true when comparing the two slopes from 1 to 2 . We can also reject at the .01 level a joint hypothesis test that the differences of the slopes are both equal to zero.

We find that stores in which one employee is observed are predicted to grant discounts with a higher probability than stores that employ four or more employees. One possible interpretation of this finding is that large-scale firms, which often employ a large number of employees at a given store, (knowingly) hire employees with an inferior ability or interest in accurately assessing a consumer's valuation, and therefore such employees are more often forbidden from granting discounts. Furthermore, the probability that our auditors interacted with someone with managerial or ownership duties is higher at stores with only one employee.

We find no significant effect of firm scale on discount size. As detailed in Section A.3 of Appendix A, our theory predicts that $\lambda$ will not influence the size of a discount for consumers who are located at the median valuation of hagglers below the posted price. Therefore, this finding would be consistent with our theory if our auditors indeed were perceived near the median valuation of consumers who ask for a discount. Unfortunately, only 47 of the 303 discounts that are offered in our data occur at what we characterize as large-scale stores, and we do not observe large variation in the prices of these products (only 16 of these 47 observations lie below the median list price). This is not surprising given that our theory predicts that fewer large-scale firms will be selected into the set of observations for which we observe a positive discount due to the increasing relationship between a firm's ability to assess consumer's valuations and its propensity to bargain.

Other controls. Recalling that we control for five store categories in our analysis and distinguish within each category between low-priced stores and high-priced stores, according to the specification reported in the first column of Table 6 we predict an approximately $70 \%$ probability of earning a discount on what we classify as expensive jewelry (not shown in Tables 6 and 7). No other store category exceeds a predicted probability of $45 \%$. In addition, jewelry is the only store category for which auditors are predicted to earn a discount with a significantly higher probability for more expensive stores within-category. One potential explanation for auditors receiving discounts with a higher probability for products at more expensive jewelry stores relative to inexpensive ones is that the perceived percentile at which the auditor is located within the distribution of haggler valuations may be lower at higher-priced jewelry stores. It also may be that margins are higher in the jewelry industry than in others that we examine, and that this effect is more pronounced at the more expensive jewelry stores that we observe.

We also find that positive discounts are significantly smaller in size at stores at which no customers were observed. One explanation for this finding is that the presence of other customers disciplines the salesperson from offering large discounts at the risk of setting a precedent for other customers in the store. Somewhat surprisingly, we find no effect of the number of customers observed in a store on the probability of observing a discount. In an alternate specification we do not report in which the number of customers is analyzed as one variable, we find that an increase of one customer observed decreases the probability of receiving a discount 
by approximately $2 \%$. However, one drawback with specifying the number of customers in this manner is that no special distinction is made between empty stores and stores with customers, a distinction which is likely to be important in reality given the type of store that one often observes to be empty.

Although we sought to minimize the extent to which auditors gave heterogeneous impressions to the salesperson, it may be that the salesperson's judgment of an auditor's willingness to pay varied across auditors. Therefore we also account for auditor identity in our analysis. Examining the fixed effects for our 12 auditors from the specification reported in the first column of Table 6 , we find that of the 66 comparisons across all possible auditor pairings, only 5 of the 66 fixed-effect pairs were significantly different than one another. In the amount equation, 11 of the 66 fixed-effect pairs were significantly different than one another. In other words, auditors appear to have been perceived quite homogeneously by the salespeople who were approached for this study. Similarly, controlling for auditor by gender rather than via fixed effects indicates that the likelihood with which an auditor receives a discount and the size of the discount offered is not statistically different across males and females. ${ }^{33}$ In line with the findings of Ortega (2009), we find that female salespeople are statistically significantly less likely to grant discounts in a subset of specifications reported, although the effect of a salesperson's perceived age was found to be insignificant on both the probability of receiving a discount as well as discount size. Finally, we find no significant differences in the likelihood of receiving a discount or discount size across the four geographic areas visited by the auditors.

Conditional discounts. It is important to note that not all discounts were offered unconditionally. That is, of the 303 observations in which a discount was granted, in 70 of these cases the discount was contingent on payment in cash. The average cash discount was approximately $8 \%$ whereas the average non-cash discount was approximately 10\%, and distinguishing between cash and non-cash discounts does not alter our empirical results in a substantial manner. ${ }^{34}$ Furthermore, 22 of the 303 cases in which a discount was granted required the customer to be registered in some manner as a regular customer, in many cases via a membership or loyalty card. This typically would have required the auditor to provide brief personal information in exchange for a discount. In these cases, this possibility was raised by the salesperson only after a discount was requested by the auditor. ${ }^{35}$ Removing these 22 observations does not qualitatively alter our results.

\footnotetext{
${ }^{33}$ In a separate specification, when interacting the gender of the salesperson with the gender of the auditor, we also do not find any significant differences at the .05 level across any of the four types of interactions.

${ }^{34}$ Removing cash discounts from our analysis changes our results very little, particularly with regards to our variables related to product price, sale status, and firm scale. Referring to cash discounts as non-discounts also does not substantially alter our results. In both cases, significance is lost with respect to the effect of the number of employees on the likelihood of earning a discount (but signs remain the same).

${ }^{35}$ The average membership discount was approximately $7 \%$ whereas the average non-membership discount was approximately $10 \%$.
} 


\section{Conclusion}

Many retail firms are willing to supplement their posted prices with a discount. In particular, the retail firms in Vienna which we studied were prepared to grant a discount approximately $40 \%$ of the time. We find that the likelihood of receiving a discount is substantially influenced by the product's price, whether the product is on sale, and by the scale of the firm that owns the store. To our knowledge, this is the first study of bargaining across product markets as well as the first empirical study of the firm-side factors that influence the retail firm's trading mechanism.

On the firm side, this is clearly only the first step towards understanding bargaining in a retail environment. Many interesting aspects remain unstudied. For example, we believe it is important to collect more detailed information regarding products and firms, seasonal variation in sales activity, and usage of cash discounts for purposes of future research. Such information would allow for a more granular understanding of bargaining practices, which could then be linked to the larger issue of price discrimination among retail firms.

Beyond the firm side effects, we also believe that our study raises many new questions for potential future research on consumers' willingness to engage in bargaining. In particular, recall that the median positive discount offered was 15 EUR and that only $6 \%$ of consumers indicated that they asked for discounts at retail stores. Are consumers' bargaining costs for retail goods, as measured in effort or embarrassment, actually high enough such that these findings can be reconciled with one another? Would consumers begin to ask for discounts if they became aware that they would be relatively successful? We leave these and additional questions to future research.

\section{References}

Arnold, M. A. And S. A. Lippman (1998): "Posted Prices Versus Bargaining in Markets with Asymmetric Information," Economic Inquiry, 36, 450-57.

Athey, S., J. Levin, And E. Seira (2011): "Comparing open and Sealed Bid Auctions: Evidence from Timber Auctions," The Quarterly Journal of Economics, 126, 207-257.

Ayres, I. (1991): "Fair Driving: Gender and Race Discrimination in Retail Car Negotiations," Harvard Law Review, 817-872.

Ayres, I. and P. Siegelman (1995): "Race and Gender Discrimination in Bargaining for a New Car," American Economic Review, 85, 304-21.

Backus, M., T. Blake, And S. Tadelis (2016): "On the Empirical Content of Cheap-Talk Signaling: An Application to Bargaining," Mimeo.

BAuner, C. (2015): "Mechanism Choice and the Buy-it-now Auction: A Structural Model of Competing Buyers and Sellers," International Journal of Industrial Organization, 38, 19-31. 
Bengtsson, N. (2015): "Efficient Informal Trade: Theory and Experimental Evidence from the Cape Town Taxi Market," Journal of Development Economics.

Berry, S., J. Levinsohn, And A. Pakes (1995): "Automobile Prices in Market Equilibrium," Econometrica, 63, 841-890.

Bester, H. (1993): "Bargaining Versus Price Competition in Markets With Quality Uncertainty," American Economic Review, 278-288.

(1994): "Random Advertising and Monopolistic Price Dispersion," Journal of Economics $\&$ Management Strategy, 3, 545-59.

Calvo, G. And S. Wellisz (1978): "Supervision, Loss of Control, and the Optimum Size of the Firm," Journal of Political Economy, 86, 943-952.

Camera, G. And A. Delacroix (2004): "Trade Mechanism Selection in Markets With Frictions," Review of Economic Dynamics, 7, 851-868.

Castillo, M., R. Petrie, M. Torero, And L. Vesterlund (2013): "Gender Differences in Bargaining Outcomes: A Field Experiment on Discrimination," Journal of Public Economics, 99, 35-48.

Cragg, J. G. (1971): "Some Statistical Models for Limited Dependent Variables With Application to the Demand for Durable Goods," Econometrica, 829-844.

De Loecker, J. And F. Warzynski (2012): "Markups and Firm-Level Export Status," American Economic Review, 102, 2437-71.

Desai, P. S. And D. Purohit (2004): "“Let Me Talk to My Manager": Haggling in a Competitive Environment," Marketing Science, 23, 219-233.

Einav, L., C. Farronato, J. D. Levin, and N. Sundaresan (2013): "Sales Mechanisms in Online Markets: What Happened to Internet Auctions?" Mimeo.

Gill, D. And J. Thanassoulis (2009): "The Impact Of Bargaining On Markets With Price Takers: Too Many Bargainers Spoil The Broth," European Economic Review, 53, 658-674.

Gill, D. And J. E. Thanassoulis (2016): "Competition In Posted Prices With Stochastic Discounts," Economic Journal, 126.

GoldberG, P. K. (1996): "Dealer Price Discrimination In New Car Purchases: Evidence From The Consumer Expenditure Survey," Journal of Political Economy, 622-654.

Hammond, R. G. (2010): "Comparing Revenue From Auctions And Posted Prices," International Journal of Industrial Organization, 28, 1-9. 
Heckman, J. J. (1976): "The Common Structure Of Statistical Models Of Truncation, Sample Selection And Limited Dependent Variables And A Simple Estimator For Such Models," in Annals of Economic and Social Measurement, Volume 5, number 4, NBER, 475-492.

Huang, G. (2010): "Posted Price and Haggling in the Used Car Market," Mimeo.

Iyer, R., A. Malenko, And A. Schoar (2016): "Reputation, Contract Renegotiation and Price Rigidity," Mimeo.

Jindal, P. And P. Newberry (2017): "To Bargain or not to Bargain: the Role of Fixed Costs in Price Negotiations," Mimeo.

Johnson, J. P. And D. P. Myatt (2006): "On the Simple Economics of Advertising, Marketing, and Product Design," American Economic Review, 96, 756-784.

Keniston, D. (2011): "Bargaining and Welfare: A Dynamic Structural Analysis of the Autorickshaw Market," Mimeo.

KwokA, J. E. (1979): "The Effect of Market Share Distribution on Industry Performance," The Review of Economics and Statistics, 101-109.

Lewis, T. R. And D. E. M. Sappington (1994): "Supplying Information to Facilitate Price Discrimination," International Economic Review, 35, 309-27.

List, J. A. (2004): "The Nature and Extent of Discrimination in the Marketplace: Evidence From the Field," The Quarterly Journal of Economics, 49-89.

Mahoney, T. And L. Sloane (1966): The Great Merchants: America's Foremost Retail Institutions and the People Who Made Them Great, Harper \& Row.

Myerson, R. B. (1981): "Optimal Auction Design," Mathematics of Operations Research, 6, 58-73.

Nooteboom, B. (1982): "A New Theory of Retailing Costs," European Economic Review, 17, 163-186.

Ortega, J. (2009): "Why Do Employers Give Discretion? Family Versus Performance Concerns," Industrial Relations: A Journal of Economy and Society, 48, 1-26.

Ostrovsky, M. And M. Schwarz (2011): "Reserve Prices in Internet Advertising Auctions: A Field Experiment," in Proceedings of the 12th ACM conference on Electronic commerce, ACM, 59-60.

Perry, M. (1986): "An Example of Price Formation in Bilateral Situations: A Bargaining Model With Incomplete Information," Econometrica, 313-321. 
RADNER, R. AND T. VAN ZANDT (1995): The Economics of Informational Decentralization: Complexity, Efficiency, and Stability, Springer Science and Business Media, chap. 10, 243280.

Raskovich, A. (2007): "Competition or Collusion? Negotiating Discounts Off Posted Prices," International Journal of Industrial Organization, 25, 341-354.

Riach, P. A. AND J. Rich (2002): "Field Experiments of Discrimination in the Market Place," The Economic Journal, 112, F480-F518.

Riley, J. And R. Zeckhauser (1983): "Optimal Selling Strategies: When to Haggle, When to Hold Firm," The Quarterly Journal of Economics, 98, 267-289.

Schmidt, C. M. And K. F. Zimmerman (1991): "Work Characteristics, Firm Size and Wages," The Review of Economics and Statistics, 73, 705-710.

Scott Morton, F. M., J. Silva-Risso, And F. Zettelmeyer (2011): "What Matters in a Price Negotiation: Evidence from the U.S. Auto Retailing Industry," Quantitative Marketing and Economics, 9, 365-402.

Sobel, J. AND I. TAKahashi (1983): "A Multistage Model of Bargaining," The Review of Economic Studies, 50, 411-426.

Vuong, Q. H. (1989): "Likelihood Ratio Tests for Model Selection and Non-nested Hypotheses," Econometrica, 307-333.

Wang, R. (1995): "Bargaining Versus Posted-Price Selling," European Economic Review, 39, $1747-1764$.

Wang, X., A. Montgomery, and K. Srinivasan (2008): "When Auction Meets Fixed Price: a Theoretical and Empirical Examination of Buy-it-now Auctions," Quantitative Marketing and Economics, 6, 339-370.

Williamson, O. (1967): "Hierarchical Control and Optimum Firm Size," Journal of Political Economy, 75, 123-138.

Wooldridge, J. M. (2010): Econometric Analysis of Cross Section and Panel Data, MIT press.

Zhang, X., P. Manchanda, And J. Chu (2017): “'Meet Me Halfway': The Value of Bargaining," Mimeo.

Zussman, A. (2013): "Ethnic Discrimination: Lessons From the Israeli Online Market for Used Cars," The Economic Journal, 123, F433-F468. 


\section{Appendix A: Theory}

\section{A.1 The firm's bargaining policy}

We begin by analyzing the circumstances under which a firm will forbid bargaining entirely. If the firm never allows the clerk to bargain, the profit per haggler is simply

$$
\pi_{0}=\mu p
$$

which is the price times the probability that a haggler is willing to pay the posted price.

Now let us consider the profit per haggler when the firm allows the salesperson to bargain with consumers whom the salesperson judges to have a valuation below the posted price. In this case, let us first consider the case when the haggler's valuation is above $p$. With probability $\lambda$ the clerk will correctly assess $v$ and will not grant a discount. With probability $1-\lambda$ the clerk perceives a random haggler, which means that with probability $\mu$ he still judges the consumer's valuation to be above $p$ and (correctly) declines the request. However, with probability $1-\mu$ he mistakenly determines that $v<p$ and grants a discount, the magnitude of which depends on a specific realization of $s$. Therefore, the frequency with which the clerk will grant discounts to hagglers with $v>p$ will decrease with the values of $\lambda$ and $\mu$.

Now let us consider the case in which the haggler's valuation is below $p$. With probability $\lambda$ the clerk assesses $v$ accurately, grants a discount, and charges the consumer a price equal to $v$. With probability $1-\lambda$, the clerk's signal is random. In such a case, with probability $\mu$ he declines to grant a discount, in which case the consumer walks away. With probability $1-\mu$, the salesperson offers a discount. However, the consumer will only accept this offer if $s<v$.

In any case in which a discount is granted and accepted by the consumer, the firm must pay $b .^{36}$ Therefore, given all the above, the profit per haggler when the owner allows for haggling is

$$
\begin{aligned}
\pi_{1} & =\mu\left[\lambda p+(1-\lambda)\left(\int_{0}^{p} \frac{(1-\mu)}{p}(s-b) d s+\mu p\right)\right] \\
& +\int_{0}^{p}\left[\lambda(v-b)+(1-\lambda) \int_{0}^{v} \frac{(1-\mu)}{p}(s-b) d s\right] \frac{(1-\mu)}{p} d v .
\end{aligned}
$$

The owner will allow its salespeople to grant discounts to consumers who are judged to possess a valuation that is lower than the posted price only if the profit per haggler from haggling is higher than the profit from not haggling, or $\pi_{1}-\pi_{0}>0$. That is, the firm will allow haggling if and only if:

$$
\frac{2 \lambda+1-4 \mu(1-\lambda)}{3(\mu(1-\lambda)+\lambda+1)} p-b>0
$$

It is easy to verify that the LHS of the above inequality is decreasing in $\mu$ and $b$. Intuitively,

\footnotetext{
${ }^{36}$ Alternatively we could have assumed that $b$ is paid by the firm even when a discount offer is declined by a consumer, which would be consistent with some interpretations of $b$. This is ultimately of little qualitative importance for the model, which is deliberately stylized.
} 
if a large percentage of hagglers would be willing to pay the posted price (high $\mu$ ) and the bargaining cost is high, then bargaining is less attractive relative to the posted price. One intuitive implication of the inequality is that a firm will always forbid bargaining when $b$ exceeds $\frac{p}{2}$. That is, the owner will not allow bargaining regardless of the clerk's attentiveness or ability $(\lambda)$ and regardless of the proportion of hagglers $(\mu)$ who are willing to pay the posted price because the most the owner can earn per haggler by allowing the clerk to discriminate between hagglers and non-hagglers is $\frac{p}{2}$. Also note that when $b<\frac{p}{2}$, the LHS of (8) is increasing in $\lambda$. Therefore, when $b$ lies in the range that is relevant for the firm's bargaining decision, it is more likely that the inequality will be satisfied for a high value of $\lambda$. Also note that when $\mu>0.25$, the inequality will not be satisfied if $\lambda<\frac{4 \mu-1}{2(2 \mu+1)}$, and likewise when $\lambda<0.5$, the inequality will not be satisfied if $\mu>\frac{2 \lambda+1}{4(1-\lambda)}$. Such scenarios may occur even if $b=0$. Intuitively, the firm may forbid bargaining in such cases because a relatively inattentive or unskilled clerk faces a sufficiently high proportion of hagglers who would have been willing to pay the posted price. To summarize, the owner will allow the clerk to offer a discount to a consumer whose valuation is judged to be below the posted price when $p$ is high, $\lambda$ is high, $b$ is low, and $\mu$ is low.

Now for the following discussion let us assume that $b<\frac{p}{2}$ so that the owner does not necessarily forbid the salesperson to haggle. We may then rewrite (8) by isolating $\lambda$ (alternatively, we could have chosen any of the other three parameters) and obtain a threshold $\bar{\lambda}$ above which the firm will not forbid haggling, which will be useful for our forthcoming discussion:

$$
\bar{\lambda}(p, b, \mu) \equiv \frac{3 b(\mu+1)+(4 \mu-1) p}{2(2 \mu+1) p-3 b(1-\mu)}
$$

\section{A.2 The salesperson's bargaining decision}

Even if the firm allows for its salespeople to bargain, the salesperson may decline a consumer's request for a discount based on the signal she receives regarding the consumer's valuation. It is therefore also useful to derive the probability of a salesperson granting a discount.

Now let us assume that $v<p$, so that we may analyze the probability that a haggler who is not willing to pay the posted price will receive a lower price offer (this assumption makes little practical difference for our analysis, which we will note shortly). In this case, the probability of receiving a discount when a consumer has valuation $v$, denoted by $\omega$, is given by

$$
\omega= \begin{cases}0 & \text { if } \lambda \leq \bar{\lambda}(p, b, \mu) \\ \lambda+(1-\lambda)(1-\mu) & \text { if } \lambda>\bar{\lambda}(p, b, \mu)\end{cases}
$$

The last line follows from $v<p$ and from the fact that a discount will be offered either when the clerk's signal is correct or when the signal is random and below $p$. As is clear, the probability of offering a discount is (weakly) increasing in $\lambda$ because it is independent of $\lambda$ when $\lambda \leq \bar{\lambda}(p, b, \mu)$ and it is increasing in $\lambda$ when $\lambda>\bar{\lambda}(p, b, \mu) .{ }^{37}$

\footnotetext{
${ }^{37}$ We note here that due to the convenient form of the signaling technology, once $\lambda$ exceeds $\bar{\lambda}$, the probability that a discount is given does not depend on $v$, which is because if it is below $p$, the signal is either exactly equal to $v$, in which case the discount is granted, or it is random, in which case the signal, and thus the probability
} 
Furthermore, the probability that a discount will be offered is increasing in $p$ because an increase in $p$ will result in a decrease in $\bar{\lambda}$, leading to an increase in $\omega$ from zero to the positive value $\lambda+(1-\lambda)(1-\mu)$ for products and firms associated with a given set of parameters. Likewise, the probability that a discount will be granted is decreasing in $b$ and $\mu$ for analogous reasons, noting further that an increase in $\mu$ also enters directly into the determination of $\omega$ whenever $\lambda>\bar{\lambda}(p, b, \mu)$.

These considerations are illustrated in Figure A. 1 for $p=1$ and $\mu=1 / 3$. In the shaded area (high $\lambda$ and low $b$ ) the owner will authorize haggling. The upward-sloping curve corresponds to $\bar{\lambda}$, the critical threshold for $\lambda$ above which discounts are given to consumers whose valuations are judged to be below the posted price. This threshold is increasing in $b$, and therefore the more costly is bargaining, the more attentive the clerk must be to induce the owner to allow haggling. However, if $b>0.5, \bar{\lambda}=1$, so even if the clerk can perfectly assess the customer's valuation, the owner will not allow haggling. Horizontal lines in the shaded area correspond to equal probability of a discount being given, with higher lines associated with higher probability.

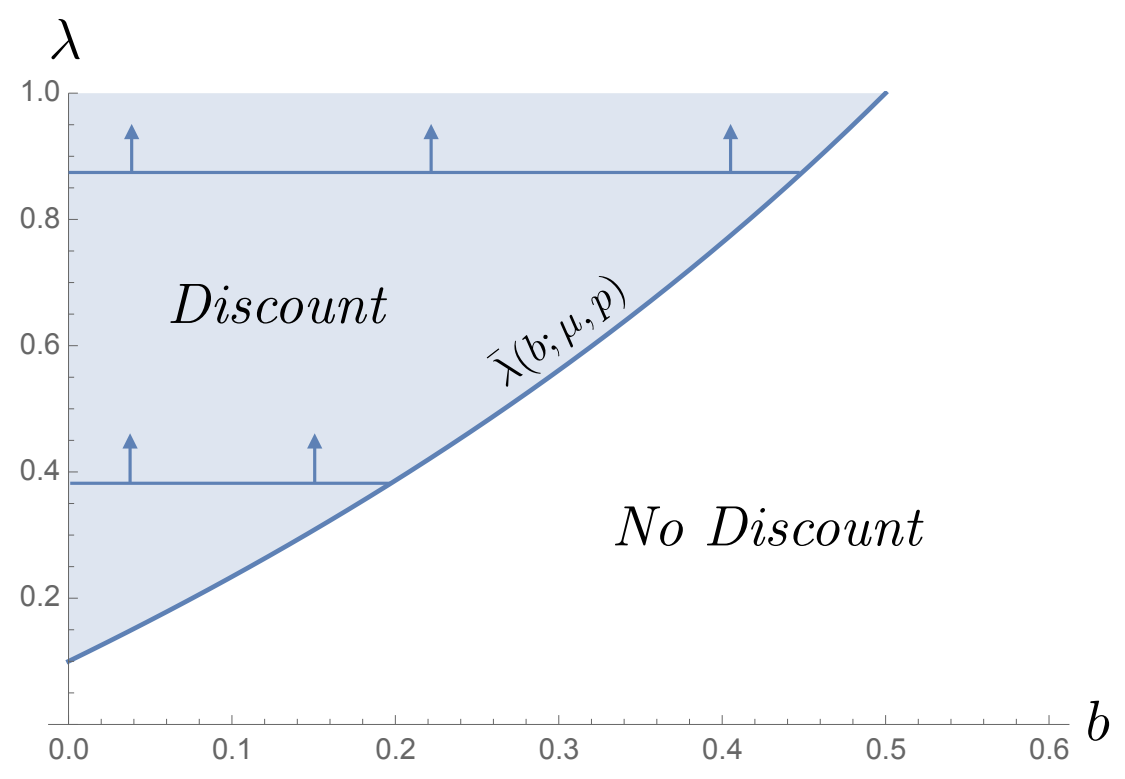

Figure A.1

More generally, if we do not restrict $v<p$ but rather $v$ is distributed according to the population of hagglers, the probability of observing a discount is simply 0 if $\lambda<\bar{\lambda}(p, b, \mu)$ and equal to $1-\mu$ if $\lambda>\bar{\lambda}(p, b, \mu)$. That is, the clerk will give a discount whenever she can perfectly evaluate that $v$ is below $p$ (which occurs with probability $\lambda(1-\mu)$ ) and whenever the randomly generated $s$ is below $p$ (which occurs with probability $(1-\lambda)(1-\mu)$ ), and these two probabilities sum to $1-\mu$. Returning to Figure A.1, the only difference in the graph in such a case is that an increase is $\lambda$ will no longer increase the possibility of a discount if the firm already permits haggling (the upper-left quadrant).

of a discount being offered, does not depend on $v$. 


\section{A.3 Discount size}

We now turn from the issue of the discount probability to the issue of the average observed discount size, conditional on the discount being granted. If $v<p$ and the discount is granted, the average price offered is

$$
\frac{1}{(1-\mu)(1-\lambda)+\lambda}\left(\lambda v+(1-\lambda) \int_{0}^{p} s \frac{(1-\mu)}{p} d s\right)=\frac{(1-\mu)(1-\lambda) p+2 \lambda v}{2(1-\mu(1-\lambda))}
$$

which yields an average discount of

$$
d=\frac{p(1+\lambda-\mu(1-\lambda))-2 \lambda v}{2(1-\mu(1-\lambda))} .
$$

To better understand $d$, let $r$ stand for the percentile a consumer occupies in the distribution of consumers between 0 and $p(r=v / p$ so that, e.g., $r=0.5$ implies that a consumer's true valuation is at the 50th percentile of consumers whose valuation is below $p$ ), and let $r$ be independent of $p$, i.e. a given consumer occupies the same percentile regardless of the price. Then we can write

$$
d=p\left[\frac{1}{2}+\frac{\lambda}{(1-\mu(1-\lambda))}(1 / 2-r)\right]
$$

which shows that the discount amount is proportional to the price (margin), and is equal to exactly half the price for the consumer at the 50th percentile, but is lower for consumers whose valuations are above the median, and higher for those whose valuations are below the median. As expected, the average discount size is increasing in $p$, and therefore a firm with a higher price will offer a larger discount. With regards to $\lambda$, the comparative statics are more nuanced. Namely,

$$
\frac{\partial d}{\partial \lambda}=\frac{p(1-\mu)(1 / 2-r)}{(1-\mu(1-\lambda))^{2}}
$$

This expression is zero for the median consumer $(r=1 / 2)$, is negative for a consumer above the median, and positive otherwise. This means that if the consumer's true valuation is equal to the median valuation of hagglers, then the average discount amount is independent of the clerk's signal precision. If the true valuation is above this median, then the more precise the clerk is, the lower is the discount amount. This is intuitive given that under full information $(\lambda=1)$, the discount is equal to $p-v$, whereas without any information $(\lambda=0)$, it is $\frac{p}{2}$.

More generally, conditional on a discount being observed, instead of our interest in the average price offered to a consumer with $v<p$, suppose we are interested in the average price when $v$ is distributed according to the population of hagglers. Since we assume that the proportion $1-\mu$ of hagglers' valuations are distributed uniformly on $[0, p]$, it is easy to see that the average exact evaluation of $v$ by the clerk is $\frac{p}{2}$ and the average random signal, conditional on a discount being offered, is also $\frac{p}{2}$. Therefore, when considering the entire population of 
hagglers, the average discount price offered conditional on a discount being granted is simply $\frac{p}{2}$.

\section{Appendix B: Auditor Behavior}

\section{B.1 Auditor product choices}

The auditors were given the freedom to choose any product within a particular price range. This means that there were two variables which the auditor could in effect influence in their search for a product - the product's price and whether the product was a sale item. One concern would be if there was a large degree of heterogeneity in the percentile of the price range chosen across auditors. Likewise, if individual auditors chose a significantly different percentage of sale items relative to other auditors, the same concern would apply.

In Table B.1 we display summary statistics of the average price percentile at which each auditor chose a product within the assigned price range. While auditors $\# 1$, \#4, and \#6 chose relatively low prices within the assigned range on average, overall it does not appear that auditors chose prices near either end of the price range. Here we use the term "percentile" loosely as we do not know the distribution of prices at a given store within a particular price range; however we surmise that in any given price range that there will be typically be a larger number of products at the lower end of the range than at the higher end. In Table B.1 we also display summary statistics of the average number of instances in which an auditor chose a product that was on sale.

\section{B.2 Pairwise behavior of auditors / honesty}

As noted in Section 3, we concealed the identities of the auditors from one another during the project. Nevertheless, while unlikely, it is possible that one or more of our auditors discovered the identities of one or more of the auditors working on the project during the data collection period. If this were the case, one concern that might arise is that an auditor who was assigned the same store as another auditor would use data collected by that auditor in order to fabricate what he or she considered to be realistic results from that store without actually carrying out the observation assignments. This would only be a concern in the second period because first period data were submitted prior to the beginning of the second period. Examining 66 possible auditor pairs during the first period, of stores that were visited twice, the median number of stores for which a given auditor pair was mutually assigned was one, the mode was zero, and the maximum number of mutual store assignments was seven.

Examining 66 possible auditor pairs over both periods, a given auditor pair was allocated a median of 10 mutually assigned stores and a maximum of 17 mutually assigned stores. For each of the 66 auditor pairs, we calculated the percentage of observations for which they both recorded a discount for the same store, the percentage of observations for which they both recorded not receiving a discount for the same store, and the percentage of observations for 
which one auditor received a discount and the other auditor did not receive a discount. Both auditors were offered a discount just over one quarter of the time whereas neither auditor was offered a discount nearly half of the time. There were no auditor pairs which always recorded a discount at mutually visited stores and one out of 66 auditor pairs always recorded not receiving a discount at mutually visited stores (8 stores, or 16 total observations). Therefore we feel comfortable that there does not appear to be evidence that auditors fabricated observations based on data collected by fellow auditors.

\section{B.3 Effect of first auditor visit on subsequent visits to the same store}

It is also worthwhile to check whether a particular auditor, by visiting a store first, somehow contaminated the observations that followed at the same store. This might occur if, for example, an auditor inadvertently angered a salesperson during his or her interaction by asking for a discount (for one of a variety of possible reasons). This could result in a very small number of discounts subsequently granted at stores at which that particular auditor visits. Although our sample size is relatively small for any given "leading" auditor, restricting our analysis to stores which appear three times in our dataset in Table B.2 we do not find evidence that a particular auditor visiting a store first led to a substantially lower incidence of discounts afterward at the same store.

In Table B.3 we restrict follower auditors to those that observed a store within the same week as the leading auditor. When analyzing the data in this fashion we are dealing with a small sample size, but we report these summary statistics nevertheless. In Columns 2 and 3 we report the outcomes related to observations at the same store between Dec 9 - Dec 14 and in Columns 4 and 5 we report the outcomes related to observations at the same store between Dec 27 - Jan 4. Auditors who follow auditor \#10 do record a particularly low number of discounts in both periods ( 2 of 10 observations and 0 of 7 observations, respectively), however this does not appear to occur for any of the other auditors.

\section{B.4 Missed observations and errors}

We now address the observation assignments that were not performed as well as observations that were performed but which contained errors. Our analysis uses 751 out of 861 total observation assignments. Of the 110 observations that we do not analyze, 84 observations were never performed. Of these 84 observations, in approximately 75 percent of these cases the auditor visited the store when it was closed. Nearly all of the remaining 25 percent of observations were not performed either because the auditor could not find a product with a posted price for which he or she could credibly bargain or because the auditor did not properly locate the store for one reason or another. Furthermore, there were five observations that were mistakenly unassigned. One characteristic of nearly all of these 84 observations is that they pertain to small-scale stores. 
The 26 remaining observations contained errors, ambiguities, inconsistencies, or applied to stores which in retrospect should not have been included in the sample due to the nature of the product sold. For example, one store's focus is bathroom and pool installation (three observations), and another store is a non-profit organization that sells used clothes (three observations). Eight observations utilized products outside of the posted price range of 30 1,000 EUR, four observations were recorded on products for which there was no posted price, and eight observations were recorded with ambiguities or inconsistencies (e.g., a discount was granted but the size of the discount was not stated explicitly or recorded).

\section{B.5 Auditor performance over time}

\section{Hot hand}

We perform several tests in order to examine the extent to which discount outcomes for a particular auditor vary over time. First, for each individual auditor, we run a simple vector autoregression (VAR) in which the dummy variable indicating whether a discount was granted is the dependent variable and the right hand side variables include lags of the dependent variable as well as all of the explanatory variables that appear in the first column of Table 6 (but without any interactions). Lag-order selection statistics using the Schwarz criterion (SBIC) support the inclusion of no lags of the dependent variable for the majority of auditors and lag-order selection statistics using the Akaike Information Criterion (AIC) support using the inclusion of no lag or one lag for the majority of the auditors. Therefore, we do not have strong evidence that previously observed discount outcomes affect an auditor's subsequent discount outcomes. We also run a Prais-Winsten regression using the same variables (without lags of the dependent variable and without interactions) in order to check for the presence of unobserved serial correlation but we find no evidence of any type of serial correlation.

\section{Learning and fatigue}

In order to address the question of whether there is a deterministic trend with regards to the rate with which auditors obtain a discount, we run a simple linear probability model with the same regressors as in the previous specification and also include a variable that tests for the existence of a deterministic trend, the order in which the auditor visited the store. We run this regression separately for each of the 12 auditors. The trend variable is negative and significant for two of the auditors at the .05 level (magnitudes of -.014 and -.021), one of the auditors at the .1 level (magnitude of .013), and insignificant for the remainder of the auditors. A positive and significant estimate might have suggested evidence of learning. We cannot rule out the possibility that a negative coefficient might suggest that a particular auditor exerted less effort in obtaining a discount over time. 
Table B.1: Average price percentile and percentage of sale items chosen by auditor identity

$\begin{array}{ccccc}\text { Auditor ID } & \text { Pctile of assigned range (avg) } & \text { St. Dev. } & \text { Sale items observed (pct) } & \text { St. Dev. } \\ 1 & 0.365 & 0.271 & 0.149 & 0.359 \\ 2 & 0.425 & 0.342 & 0.133 & 0.343 \\ 3 & 0.513 & 0.341 & 0.279 & 0.452 \\ 4 & 0.372 & 0.355 & 0.323 & 0.471 \\ 5 & 0.525 & 0.304 & 0.182 & 0.389 \\ 6 & 0.376 & 0.308 & 0.305 & 0.464 \\ 7 & 0.515 & 0.32 & 0.233 & 0.427 \\ 8 & 0.425 & 0.339 & 0.185 & 0.392 \\ 9 & 0.512 & 0.312 & 0.231 & 0.425 \\ 10 & 0.509 & 0.305 & 0.292 & 0.458 \\ 11 & 0.441 & 0.312 & 0.172 & 0.38 \\ 12 & 0.469 & 0.343 & 0.213 & 0.413\end{array}$

Table B.2: Discounts granted to auditors that followed a particular auditor at the same store (three observations per store required)

\begin{tabular}{|c|c|c|c|c|c|c|}
\hline \multirow[b]{2}{*}{ Leader ID } & \multicolumn{2}{|c|}{ First follower } & \multicolumn{2}{|c|}{ Second follower } & \multicolumn{2}{|c|}{ Both followers } \\
\hline & Discounts & Observations & Discounts & Observations & Discounts & Observat \\
\hline 1 & 4 & 10 & 4 & 10 & 8 & 20 \\
\hline 2 & 8 & 18 & 6 & 18 & 14 & 36 \\
\hline 3 & 9 & 16 & 5 & 16 & 14 & 32 \\
\hline 4 & 12 & 23 & 6 & 23 & 18 & 46 \\
\hline 5 & 5 & 19 & 6 & 19 & 11 & 38 \\
\hline 6 & 7 & 15 & 5 & 15 & 12 & 30 \\
\hline 7 & 6 & 19 & 5 & 19 & 11 & 38 \\
\hline 8 & 7 & 16 & 6 & 16 & 13 & 32 \\
\hline 9 & 13 & 25 & 9 & 25 & 22 & 50 \\
\hline 10 & 8 & 19 & 5 & 19 & 13 & 38 \\
\hline 11 & 7 & 16 & 6 & 16 & 13 & 32 \\
\hline 12 & 5 & 15 & 3 & 15 & 8 & 30 \\
\hline
\end{tabular}

Table B.3: Discounts granted to auditors that followed a particular auditor at the same store within the same week

Leader \& follower visit pre-xmas

Leader ID Follower Discounts Follower Obs.
Leader \& follower visit post-xmas Follower Discounts Follower Obs.

$\begin{array}{ccccc}1 & 2 & 6 & 7 & 20 \\ 2 & 5 & 8 & 7 & 10 \\ 3 & 7 & 10 & 1 & 11 \\ 4 & 5 & 10 & 1 & 9 \\ 5 & 4 & 8 & 3 & 9 \\ 6 & 4 & 11 & 4 & 10 \\ 7 & 7 & 10 & 2 & 8 \\ 8 & 5 & 16 & 2 & 5 \\ 9 & 9 & 10 & 0 & 7 \\ 10 & 2 & 10 & 2 & 5 \\ 11 & 4 & 9 & 1 & 7 \\ 12 & 3 & & & \end{array}$

Note: Auditors \#1-\#6 are females and auditors \#7-\#12 are males. 
Figure B.1: Written instructions given to the auditors

Dear All,

Please read this text very carefully and follow it precisely. Have a copy with you to consult safely tucked away in your pocket. It's crucial for our study that all issues mentioned below are taken into account. One of us will call you on Monday morning to review this with you and make sure everything is clear.

Please take a look at your assignment carefully. If you do not wish or are able to visit some stores for reasons such as you are uncomfortable visiting the store, you have some conflict of interest, etc., please let us know immediately so that you are reassigned to other stores.

The first bargaining period will occur between December 9 - December 14 and the second bargaining period will occur between December 27 - January 4. In the attached spreadsheet you will find your bargaining assignments. This includes a store name, address, type of the store, interval of prices (more about this below), and restriction on when to visit the store (some stores will have no restrictions). Each of you will receive about 35-40 to be visited between Dec 9 and Dec 14, and approximately the same quantity between December 27 and January 4 . So overall you will visit 70-80 stores. You were randomly assigned to different periods, so it may happen that in a 3-day window you need to do up to 16 shops. Please plan ahead and if you anticipate problems, let us know immediately.

Furthermore, a given store may have a date restriction for a given period. For example, if Store $\mathrm{A}$ is assigned to you in the period Dec 9 - Dec 14, you may be required to perform this observation at some time between Dec 9 - Dec 11, or alternatively between Dec 12 - Dec 14 . If it is assigned to you in the second period, you may be required to visit between Dec 27 - Dec 31, or alternatively between Jan 2 - Jan 4. This information will be provided to you in your assignment spreadsheet.

You should dress in a similar way for every observation. You should dress nicely, but not overly so (no ties, no suits, no evening dresses etc.). No sneakers. Do not carry a backpack. If you wear jeans, wear a nice pair. For men, shirt should be tucked in, you should be shaved, closely trimmed, or have a properly trimmed beard. For women, everyday makeup is $O K$.

For each store you will receive a price interval in which to find a product. For example, you will need to find something between 45 and 120 euros in shop X. As we discussed, you need to find something in which you could show genuine and credible interest. If no such product can be found in the interval, find a product closest to the interval for which you can credibly bargain.

Make sure that the product you choose has a price tag on it, or its price is identifiable in some other way; do not ask a salesperson for a price. If you have difficulty finding a posted price in the interval you were given because most prices are not posted, drop the store and note this in the comments section for that store. Please do not avoid or favour products on sale, just find a product for which you could show genuine and credible interest.

Once you have expressed interested in a particular product in a very brief conversation with a salesperson, ask a salesperson something along the following lines: "Can we do something about the price", "Can I get a discount", "Can I get this cheaper", or "Can we talk about the price" (everything should be done in German, unless the salesperson switches to another language that he/she prefers). Do not suggest a price you would like to pay, even if asked for it (e.g. "how much would you want to pay?") Avoid this question politely by telling them something like "I don't know, please tell me what you could offer me"). Similarly, do not suggest a percentage discount (e.g., do not suggest "can I get $10 \%$ off?")

When showing interest for a product, or bargaining for it, do not mention you are a student, unless directly asked, and do not give any other occupational details. Do not say you have little money or you are poor, but you may say that an item is a bit too expensive for you if this comes naturally in you are poor, but you may say that an item is a bit too expensive for you if this comes naturally the convers
cheaper.

If the salesperson agrees and offers a discount, find a polite way to say that you will not buy now and leave. If the salesperson denies your initial request for a discount, try to ask for a discount again in a way that is appropriate for the situation. If the salesperson denies your second request, leave.

Do not ask for a manager at any time, but if you ask for a discount and the salesperson responds by offering to speak to a manager on his/her own initiative, remain to interact with the manager (as long as the manager arrives within 5 minutes, otherwise you should leave politely).

Once you are done, record the following (and put into the appropriate column of the provided excel file when convenient) next to the store observation details that we provide for you:

1. Gender of the final person with whom you interacted (if no manager was involved, this is simply the gender of the salesperson from whom you asked for a discount)

2. Approximate age of this person in one of the following ranges (below 35,35 to 50 , or above 50)

3. Name of the good (e.g. leather bag)

4. Current price of the good (the one you would have to pay without bargaining)

5. List price of the good. List price may be the same as current price. The list price is higher if the good is currently discounted on the price tag. (e.g. if the price tag says 100 euro and is crossed out, and then says 80 euro below, list price is 100 euro, current price is 80 euro).

6. If you are granted a discount, record either the final price offered, or if the discount is given in percentages, the discount percentage. These are two separate fields; please fill out given in percentages, the discount percentage. These are two separate fields; please fill out
only one of them (e.g. if a product costs 100 euro, and the salesperson offered to sell it for 90 , you record 90 in the "final price". For the same product, if the salesperson tells you instead that you can get $10 \%$ off, then leave "final price" blank, and put $10 \%$ in "\% discount")

7. Was discount offered on the condition that cash was paid?

8. Time and date at which you exit the store

9. Anything strange/interesting that happens should be recorded in the comments section (also, if a manager/owner/superior was mentioned, put this in the comments section).

Please make sure that your observations are somewhat spread out over three different time periods: weekdays before $2 \mathrm{pm}$, weekdays after $\mathbf{2 p m}$, and Saturdays (time of the day on Saturday is not important). Do not bargain after 5:30 pm on any day. 


\section{Appendix C: Additional Figures}

Figure C.1: Distribution of prices

(a) List price

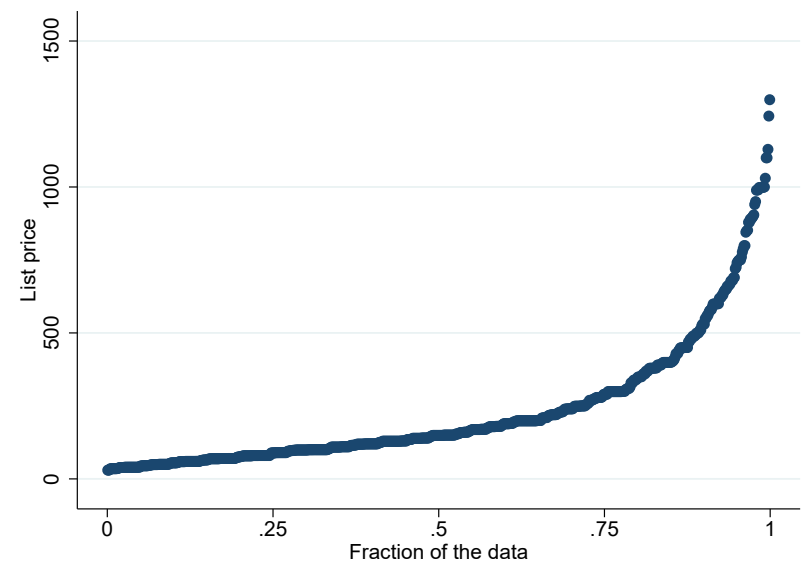

(c) Posted price

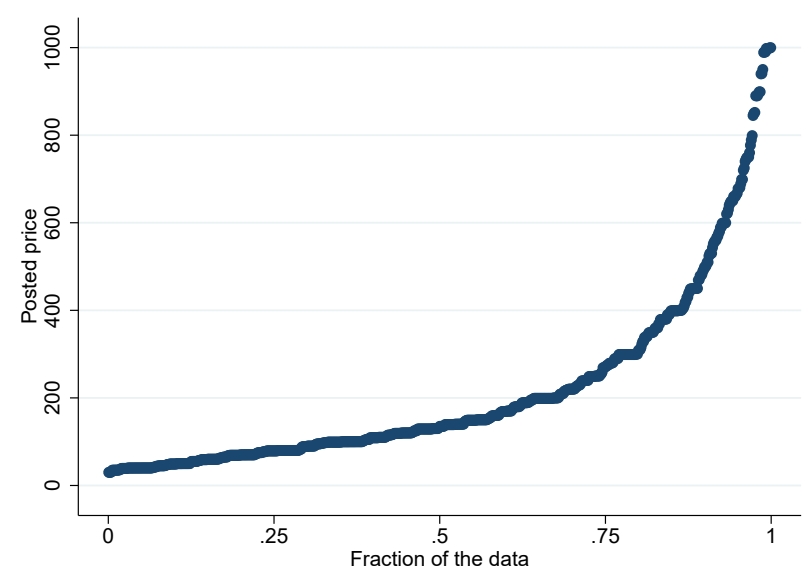

(b) $\ln$ (list price)

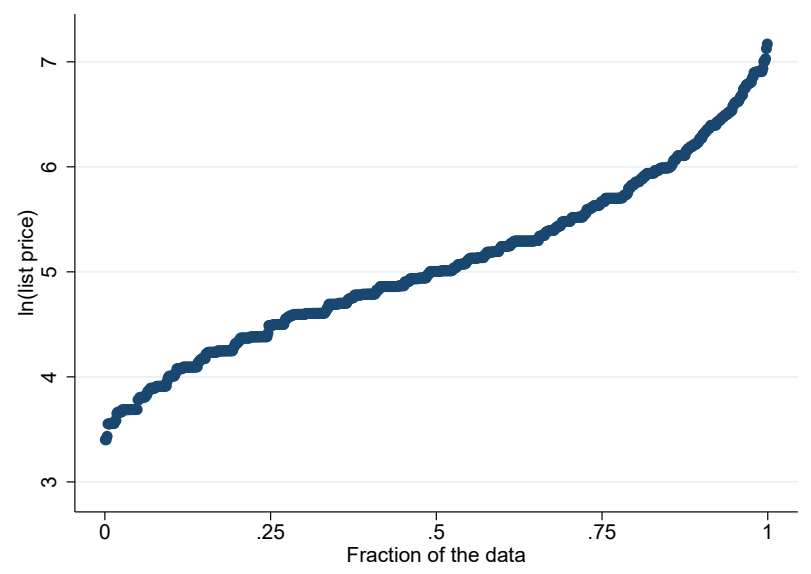

(d) $\ln ($ posted price $)$

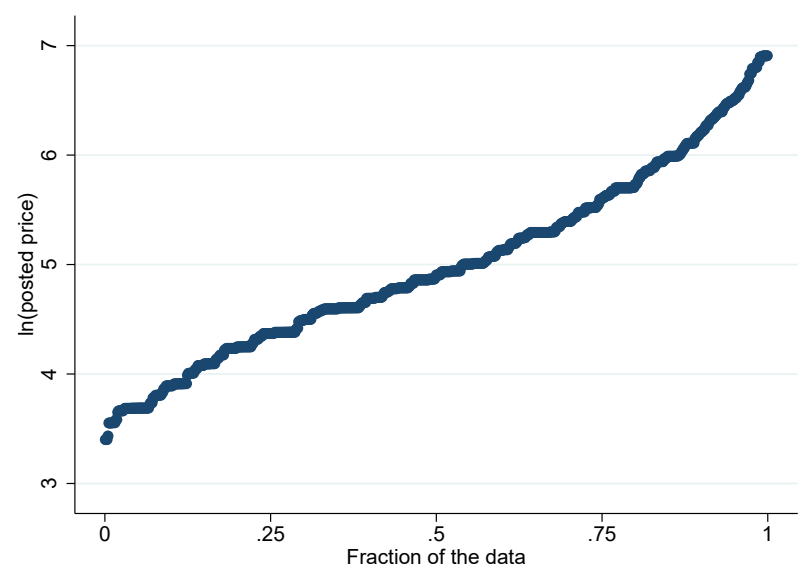

Note: One list price observation of 5,900 EUR is excluded from Figure C.1(a) and Figure C.1(b). 
Figure C.2: Predicted probability of a discount: Price and firm scale (additional specifications reported in Table 6)

(a) List price quartile and multinational reach

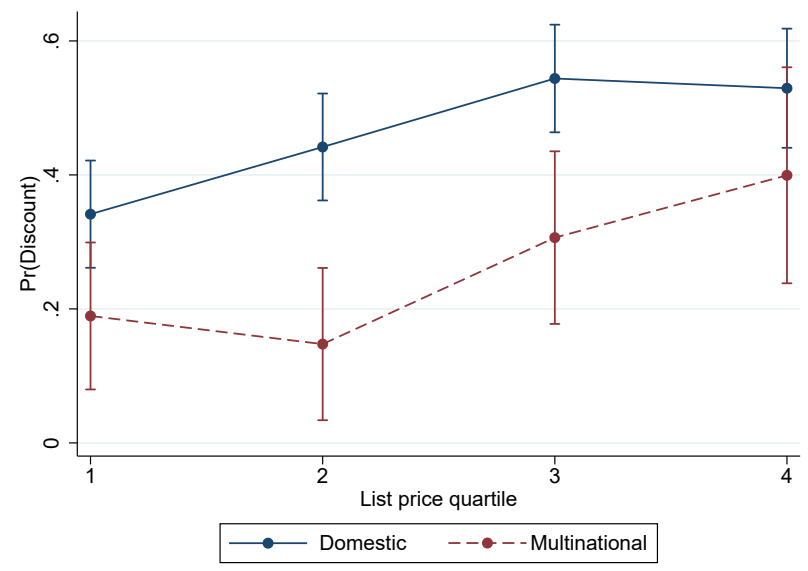

(b) List price quartile and walking seconds

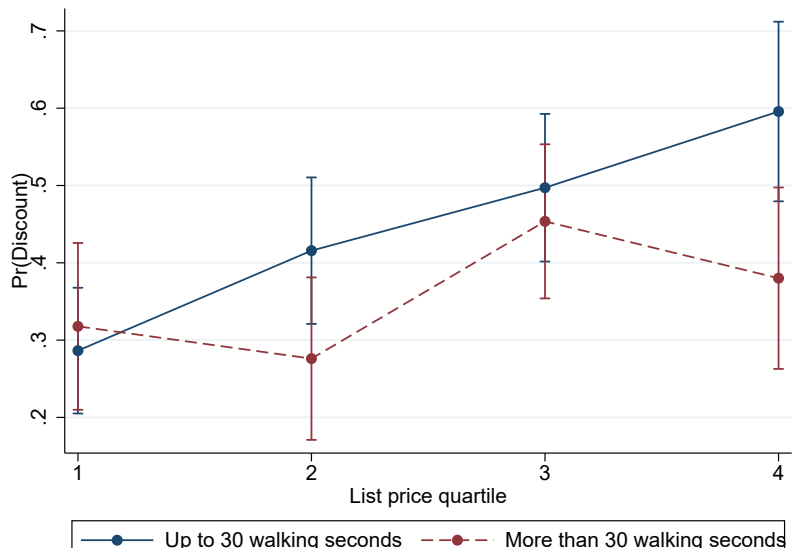

(c) List price quartile and firm scale

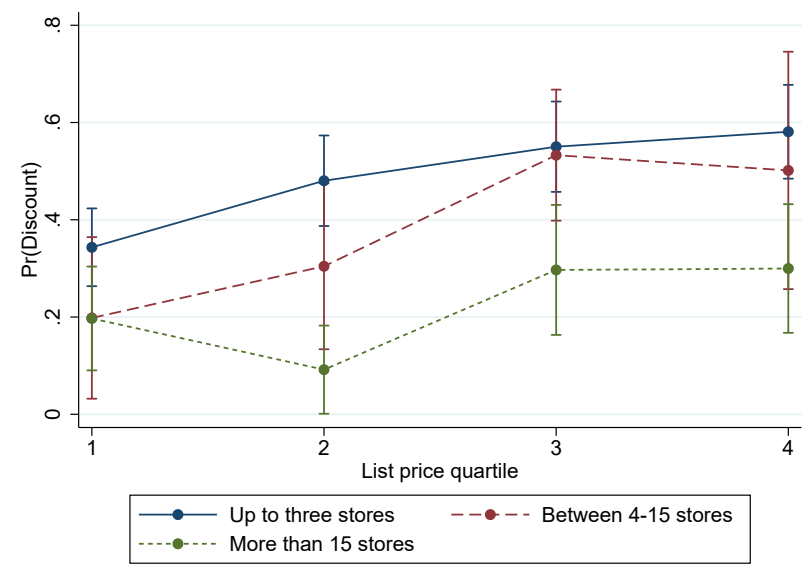


Figure C.3: Predicted probability of a discount: Price and firm scale (additional specifications reported in Table 7)

(a) List price tercile and firm scale

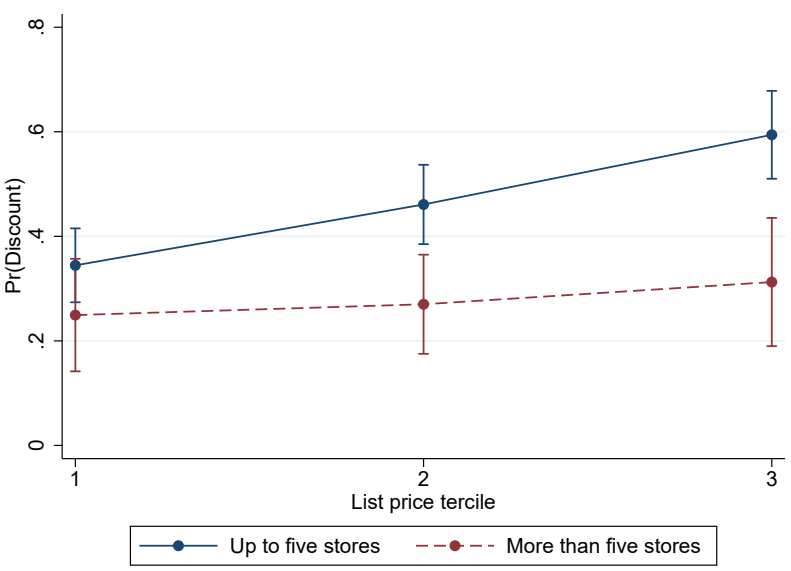

(b) $\ln$ (list price) and firm scale

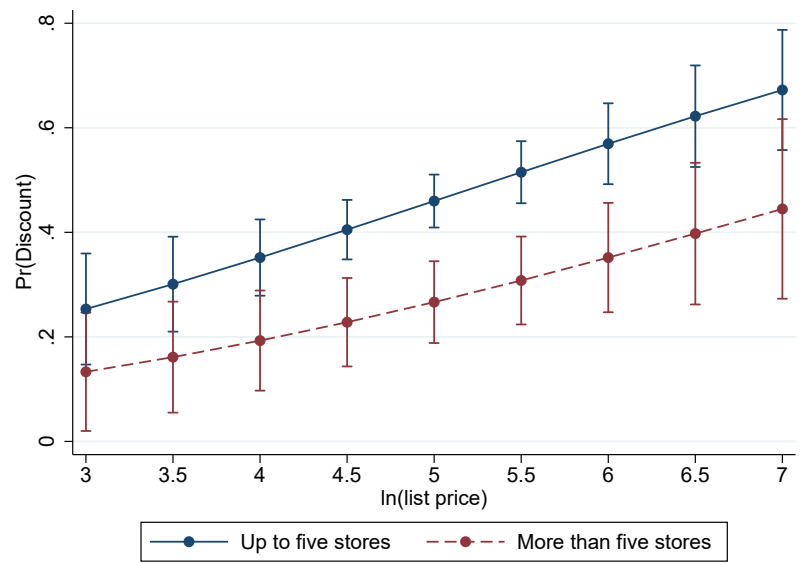

(c) Posted price quartile and firm scale

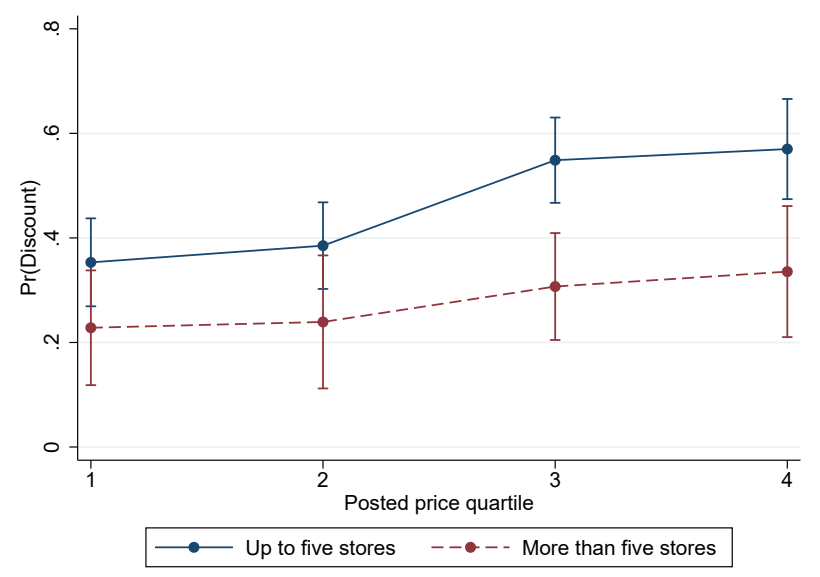

